\title{
Multi-scale dynamics and rheology of mantle flow with plates
}

\author{
Laura Alisic, ${ }^{1,2}$ Michael Gurnis, ${ }^{1}$ Georg Stadler, ${ }^{3}$ Carsten Burstedde, ${ }^{3,4}$ \\ and Omar Ghattas $3,5,6$ \\ Received 14 February 2012; revised 24 August 2012; accepted 31 August 2012; published 9 October 2012.
}

[1] Fundamental issues in our understanding of plate and mantle dynamics remain unresolved, including the rheology and state of stress of plates and slabs; the coupling between plates, slabs and mantle; and the flow around slabs. To address these questions, models of global mantle flow with plates are computed using adaptive finite elements, and compared to a variety of observational constraints. The dynamically consistent instantaneous models include a composite rheology with yielding, and incorporate details of the thermal buoyancy field. Around plate boundaries, the local resolution is $1 \mathrm{~km}$, which allows us to study highly detailed features in a globally consistent framework. Models that best fit plateness criteria and plate motion data have strong slabs with high stresses. We find a strong dependence of global plate motions, trench rollback, net rotation, plateness, and strain rate on the stress exponent in the nonlinear viscosity; the yield stress is found to be important only if it is smaller than the ambient convective stress. Due to strong coupling between plates, slabs, and the surrounding mantle, the presence of lower mantle anomalies affect plate motions. The flow in and around slabs, microplate motion, and trench rollback are intimately linked to the amount of yielding in the subducting slab hinge, slab morphology, and the presence of high viscosity structures in the lower mantle beneath the slab.

Citation: Alisic, L., M. Gurnis, G. Stadler, C. Burstedde, and O. Ghattas (2012), Multi-scale dynamics and rheology of mantle flow with plates, J. Geophys. Res., 117, B10402, doi:10.1029/2012JB009234.

\section{Introduction}

[2] Significant insight into the forces that govern plate tectonics has been gained through both global and regional studies of mantle convection with plates. Examples are the relation between slab pull and ridge push as driving forces for plate tectonics, the evolution of slabs with plate motions as kinematic boundary conditions, and the effect of radial viscosity variations on plate motions and the state of stress in plates and slabs. However, some of the questions basic to our understanding of the dynamics of the mantle and plates remain unresolved, such as the rheology and state of stress

\footnotetext{
${ }^{1}$ Seismological Laboratory, California Institute of Technology, Pasadena, California, USA.

${ }^{2}$ Now at Bullard Laboratories, University of Cambridge, Cambridge, UK.

${ }^{3}$ Institute for Computational Engineering and Sciences, University of Texas at Austin, Austin, Texas, USA.

${ }^{4}$ Now at Institut für Numerische Simulation, Rheinische FriedrichWilhelms-Universität Bonn, Bonn, Germany.

${ }^{5}$ Jackson School of Geosciences, University of Texas at Austin, Austin, Texas, USA.

${ }^{6}$ Department of Mechanical Engineering, University of Texas at Austin, Austin, Texas, USA.

Corresponding author: L. Alisic, Bullard Laboratories, University of Cambridge, Cambridge CB3 0EZ, UK. (la339@cam.ac.uk)

(C2012. American Geophysical Union. All Rights Reserved. 0148-0227/12/2012JB009234
}

of plates and slabs; the coupling between plates, slabs and mantle; and the flow around slabs.

[3] Several fundamental issues revolve around the rheology of the mantle and lithosphere; for instance the strength of plates and subducting slabs has not been uniquely determined. In regional studies constrained by the geoid, the viscosity of slabs has been inferred to be 100 to 1000 times higher than in the surrounding mantle [Moresi and Gurnis, 1996], and could not exceed $10^{23} \mathrm{~Pa}$ in order to fit geoid highs over subducted slabs [Billen et al., 2003]. Torque balance models of the Pacific and Australian plates suggested that the best fit to observed rotation poles was obtained with an effective lithosphere viscosity of $6 \times 10^{22} \mathrm{~Pa} \mathrm{~s}$ [Buffett and Rowley, 2006]. Studies that address plate bending in generic subduction zone models indicate that the plate viscosity must be between 50 and 200 times the mantle viscosity in order to reproduce observed ranges of plate velocities [Conrad and Hager, 1999], for which an effective viscosity of $10^{23} \mathrm{~Pa} \mathrm{~s}$ in the bending lithosphere is sufficient [Conrad and Hager, 2001]. Additionally, studies addressing slab morphology show that slabs must be weak (i.e., with a viscosity of $10^{23} \mathrm{~Pa}$ s or less), in order to reproduce observed trench migration [Zhong and Gurnis, 1995; Enns et al., 2005; Stegman et al., 2006]. Liu and Stegman [2011] used Farallon slab morphology from tomography models to constrain rheology of the upper mantle in time-dependent convection models, and inferred an upper mantle slab viscosity of $\sim 5 \times 10^{21} \mathrm{~Pa} \mathrm{~s}$, weakening to $1.5 \times$ $10^{21} \mathrm{~Pa} \mathrm{~s}$ in the transition zone. In contrast, with timedependent generic models of slab dynamics, strong slabs 
are inferred with viscosities of around $10^{24} \mathrm{~Pa} \mathrm{~s}$ [Billen and Hirth, 2007], assuming the experimentally determined strong temperature dependence of the effective viscosity of olivine [Hirth and Kohlstedt, 2003].

[4] Localized yielding in the hinge of a subducting slab allows slabs to be strong while continuing to move alongside the overriding plate and subduct with relative ease [Ribe, 1992]. There are several observations supporting localized weakening in hinges of subducting plates. Studies of bendingrelated faulting in the outer rise of trenches in Middle and South America show a pervasive tectonic fabric with inferred serpentinization in outer trench walls, which qualitatively suggests deformation and weakening of the subducting plate [Ranero et al., 2003; Grevemeyer et al., 2005]. Lithospheric earthquakes within the subducting oceanic plate, which are large-magnitude events on faults that completely cut through the lithosphere, provide additional evidence for permanent deformation within a trench [Kikuchi and Kanamori, 1995; Gurnis et al., 2000a]. Trench-perpendicular profiles of bathymetry in the Peru-Chile trench indicate that the effective elastic thickness of the subducting plate is reduced to $\sim 50$ $65 \%$ of the plate's mechanical thickness due to yielding [Judge and McNutt, 1991], averaged over the length scale of plate bending. Gravity measurements within the Kermadec trench allow more localized quantification of this weakening, and show that the flexural rigidity of plates is reduced by 3 to 5 orders of magnitude from the forebulge to the trench axis, which indicates that the subducting plate has little or no elastic strength there [Billen and Gurnis, 2005]. Using a composite rheology that incorporates both diffusion and dislocation creep with a nonlinear component along with yielding allows for such localization of strain, as strain weakening can reduce the viscosity in the hinge zone from $10^{24}$ to $\sim 5 \times 10^{22} \mathrm{~Pa} \mathrm{~s}$ [Billen and Hirth, 2007].

[5] Related to slab strength is the state of stress in the slab and surrounding mantle. Principal compression and tension directions have been estimated from earthquake focal mechanisms in slabs [Isacks and Molnar, 1971; Alpert et al., 2010]. Numerical mantle convection models at global [Alpert et al., 2010] and regional scales [Billen et al., 2003; Carminati and Petricca, 2010] indicate that the state of stress in slabs resulting from numerical models depends on the radial viscosity structure, and on the 3-D geometry of the subducting slabs. However, challenges to reproduce the state of stress in these studies persist, as deviations between the predicted and observed state of stress remain significant.

[6] The rheology also directly influences the manner in which plates and slabs are coupled to the surrounding mantle. The stronger plates are, the more they could exert a force on plate motions, while they act as stress guides between the upper mantle and lithosphere [Elsasser, 1969]. Global models addressing slab pull show that slabs that are strong enough to remain coupled to plates throughout subduction provide the best fit to observed plate motions, exerting slab pull forces that account for approximately $50 \%$ to $70 \%$ of the total driving forces on plates [Becker and O'Connell, 2001; Conrad and Lithgow-Bertelloni, 2002].

[7] Observations of shear wave splitting around slabs putatively provide insight on mantle flow around subducting slabs [Wiens and Smith, 2003; Long and Silver, 2008, 2009].
Accounting for the downward and/or downdip motion of subducting slabs, one would expect trench-perpendicular flow both on top of and beneath subducting slabs through viscous coupling between the subducting slab and the surrounding mantle. However, the anisotropy estimated from shear wave splitting measurements has been interpreted as implying a significant trench-parallel component to the flow, suggesting a more complex flow pattern around slabs [Long and Silver, 2008]. Wiens and Smith [2003] attributed the observed splitting to trench-parallel flow in the wedge, induced by the opening of backarc basins. Alternatively, the observed anisotropy could be caused by the presence of highly anisotropic minerals formed along faults in the subducting lithosphere [Faccenda et al., 2008]. Slab-faulting induced anisotropy would suggest that shear-wave splitting in subduction zones provides little constraint on mantle flow around slabs. Numerical mantle convection models have had limited success in reproducing the trench-parallel flow except around slab edges [Long and Becker, 2010; Jadamec and Billen, 2010], which seems to indicate that either the observed anisotropy is not fully understood, or the numerical models lack necessary components.

[8] To address these issues, numerical models of global mantle flow are developed, that incorporate significant detail in the thermal buoyancy field, and a composite rheology with yielding. An extremely high local resolution of 0.5 to $4 \mathrm{~km}$ is needed around tectonic plate boundaries and slabs to allow for localized weakening in the hinge zone of the subducting plate [Gurnis et al., 2004; Billen and Hirth, 2007], and to accommodate the orders-of-magnitude variation in viscosity over short distances between the strong, cold slabs and the weak mantle wedge [van Keken et al., 2002]. Additionally, an accurate representation of the buoyancy field for the slab requires high resolution, such that the slab can act as a stress guide [Zhong et al., 1998]. Consequently, the mesh size required in global numerical models can become too large for current generation computers. Adaptive mesh refinement (AMR) is an approach in which only the areas in a mesh with large changes in material properties over short distances have high resolution; elsewhere a low resolution is allowed. This technique reduces the total number of elements necessary in the whole mesh while still capturing the small-scale features. However, even with AMR, global mantle convection models are still large computational problems requiring several hundreds of millions of elements. Hence, a highly efficient and scalable parallel implementation is required to make these models computationally feasible on today's supercomputers [Burstedde et al., 2008, 2009].

[9] In this paper, we assess competing effects of rheological parameters and regional characteristics on mantle dynamics in instantaneous models of mantle flow. By utilizing the new computational methods available, we can study detailed regional features in a globally consistent framework. First, the methods used to compute and analyze the global mantle convection models are described. Then, we explore the effects of changes in rheological parameters on plate motions at a global scale, plateness, and net surface rotation as a first order test of the results. Models are then assessed using the strain rates and the state of stress in slabs and overriding plates. Finally, the details of regional slab dynamics are studied by 
Table 1. Parameters Used to Nondimensionalize the Mantle Flow Equations

\begin{tabular}{lcc}
\hline \multicolumn{1}{c}{ Parameter } & Symbol & Value \\
\hline Density & $\rho_{o}$ & $3300 \mathrm{~kg} \mathrm{~m}^{-3}$ \\
Gravitational acceleration & $g_{o}$ & $9.81 \mathrm{~m} \mathrm{~s}^{-2}$ \\
Thermal expansion coefficient & $\alpha$ & $2.0 \times 10^{-5} \mathrm{~K}^{-1}$ \\
Temperature scaling & $\Delta T$ & $1400 \mathrm{~K}$ \\
Thermal diffusivity & $\kappa$ & $10^{-6} \mathrm{~m}^{2} / \mathrm{s}$ \\
Reference viscosity & $\eta_{o}$ & $10^{20} \mathrm{~Pa} \mathrm{~s}$ \\
Radius & $R_{o}$ & $6.371 \times 10^{6} \mathrm{~m}$ \\
Rayleigh number & $R a=\frac{\rho_{o} g_{o} \alpha \Delta T R_{o}^{3}}{\eta_{o} \kappa}$ & $2.344 \times 10^{9}$ \\
\hline
\end{tabular}

investigating flow in and around slabs together with microplate behavior and trench rollback.

\section{Methods}

\subsection{Numerical Methods}

[10] Models of instantaneous mantle convection are computed under the Boussinesq approximation with uniform composition. The nondimensionalized strong form of the governing equations, the conservation of mass and momentum, are given by:

$$
\begin{gathered}
\nabla \cdot \mathbf{u}=0, \\
\nabla \mathbf{p}-\nabla \cdot\left[\eta(T, \mathbf{u})\left(\nabla \mathbf{u}+\nabla \mathbf{u}^{\top}\right)\right]=\operatorname{Ra} T \mathbf{e}_{r},
\end{gathered}
$$

where $\mathbf{u}, \mathbf{p}, \eta$, and $T$ are the velocity, pressure, viscosity, and temperature, respectively, and $\mathbf{e}_{r}$ is the unit vector in the radial direction [e.g., Schubert et al., 2001]. Ra is the Rayleigh number, $\mathrm{Ra}=\alpha \rho_{o} g \Delta T R_{o}^{3} /\left(\kappa \eta_{o}\right)$, where $\alpha, \rho_{o}, \eta_{o}$, and $\kappa$ are the reference coefficients of thermal expansion, density, viscosity, and thermal diffusivity (see Table 1). $\Delta T$ is the temperature difference across the mantle, $R_{o}$ is the radius of the Earth, and $g$ is the gravitational acceleration. The boundaries at the surface and core-mantle boundary are stress-free in the tangential direction, and have zero velocity in the normal direction. Interior and surface velocities, along with viscosity, strain rate, and state of stress are model outcomes.

[11] The equations are solved with Rhea, a finite element mantle convection code designed to run on hundreds of thousands of cores (C. Burstedde et al., Rhea: Largescale adaptive mantle convection simulation, submitted to Geophysical Journal International, 2012). The code uses the octree-based p4est library [Burstedde et al., 2008, 2011] for adaptive mesh refinement. The leaves of an adaptive octree correspond to elements of a recursively subdivided hexahedral mesh, without holes or overlaps. Connecting the leaves in a tree traversal, where the sequence of eight children is always the same (we choose $z$-ordering, i.e., from lower front left, lower front right, lower back left, etc., to upper back right), creates a space-filling curve that induces a unique total ordering of all mesh elements. Recursive refinement and coarsening of an octree mesh can create neighboring elements of different sizes. The maximum size difference between neighboring elements is restricted to a factor of two (these meshes are called 2:1 balanced). A parallel partition is defined by segmenting the curve into pieces of equal number of elements. The p4est library implementing these AMR algorithms has been scaled to more than 220,000 processor cores [Burstedde et al., 2010, 2011], although only exactly 6,000 were used for the calculations here.

[12] The initial temperature field is interpolated on a finite element mesh with about 22 million elements, which is refined radially in the upper mantle. First, this initial mesh is coarsened and refined based on temperature variations. Then, the mesh is refined down to $1-2 \mathrm{~km}$ element size over the plate boundaries at the surface, which are defined as narrow low-viscosity zones $\sim 10 \mathrm{~km}$ wide. This leads to meshes with about 100 million elements. Solution of the Stokes equations begins only after these initial AMR steps. The mesh is further refined during the iterative solution of the nonlinear flow system to resolve localization of deformation. Here, element-based error indicators are used to determine which finite elements to refine (or coarsen) during the simulation. The error estimator $E$ is given by a weighted sum of the element integrals of the local temperature and viscosity gradients, and the second invariant of the strain rate:

$$
E_{e}=w_{1}\left|\nabla \eta_{e}\right|+w_{2}\left|\nabla T_{e}\right|+w_{3}\left|\nabla T_{e} \cdot \mathbf{r}\right|+w_{4} \dot{\varepsilon}_{\mathrm{II}} e,
$$

where $e$ denotes element-based quantities. The terms with gradients in viscosity and temperature allow for refinement at the transition between the cold and highly viscous plates and slabs, and the hotter and less viscous asthenosphere. The temperature gradient in the radial direction $\left(\nabla T_{e} \cdot \mathbf{r}\right)$ adds radial refinement to the mesh, essentially at the mantlelithosphere transition. Additionally, the gradient in viscosity refines the mesh around weak plate boundaries and areas with yielding. Finally, the second invariant of the strain rate adds additional refinement in the mantle wedge (where velocities tend to be high) and in the hinge zone of the subducting plate.

[13] While we apply both refinement and coarsening to the initial mesh during preprocessing, only refinement is enabled during the model run. In each iteration of the solution process we first mark $10-20 \%$ of the elements, where the error indicator is large, to be refined. Then, to improve the accuracy of mass conservation, we additionally mark elements for which the divergence of velocity (equation (1)) is large. The marked elements are then refined after this marking stage. We usually perform about 6-8 such solution-based refinements, resulting in meshes with about 200-300 million finite elements on up to 8 different refinement levels. Typical linear systems arising in our simulations have between 400 million and 1.2 billion unknowns and require a minimum of 4000 5000 processor cores for their solution.

[14] The governing equations (1) and (2) are solved iteratively by a block preconditioned Krylov method that employs an algebraic multigrid (AMG) subpreconditioner. Discretizing the Stokes equations results in the following matrix problem:

$$
Q\left(\begin{array}{l}
\mathbf{u} \\
\mathbf{p}
\end{array}\right)=\left(\begin{array}{l}
\mathbf{f} \\
0
\end{array}\right) \quad \text { with } \quad Q=\left(\begin{array}{cc}
A & B^{\top} \\
B & -C
\end{array}\right),
$$

where $\mathbf{u}, \mathbf{p}$, and $\mathbf{f}$ denote the discretized velocity, pressure and external force. The block matrices $A$ and $C$ are symmetric and positive definite and, thus, equation (4) is an indefinite 
symmetric system. $C$ is a result of the pressure stabilization, which is necessary due to the use of trilinear finite elements for both velocity and pressure [Dohrmann and Bochev, 2004; Elman et al., 2005]. For the solution with the system matrix $Q$ we employ the preconditioned minimum residual method (MINRES) [Paige and Saunders, 1975; Elman et al., 2005]. Combining MINRES with an efficient preconditioner is critical to solve systems of the size of our mantle flow simulations. To construct a preconditioner, we factor the matrix $Q$ as follows:

$$
\left(\begin{array}{cc}
A & B^{\top} \\
B & -C
\end{array}\right)=\left(\begin{array}{cc}
I & 0 \\
B A^{-1} & I
\end{array}\right)\left(\begin{array}{cc}
A & 0 \\
0 & -\left(B A^{-1} B^{\top}+C\right)
\end{array}\right)\left(\begin{array}{cc}
I & A^{-1} B^{\top} \\
0 & I
\end{array}\right),
$$

showing that $Q$ is congruent to a block diagonal matrix. Neglecting the off-diagonal terms $B A^{-1}$ and $A^{-1} B^{\top}$ motivates the use of the symmetric and positive definite matrix

$$
P=\left(\begin{array}{cc}
A & 0 \\
0 & S
\end{array}\right), \text { with } S=B A^{-1} B^{\top}+C,
$$

as preconditioner. We approximate the Schur complement $S$ with a lumped mass matrix weighted by the inverse viscosity $\left(\eta^{-1}\right)$, motivated by spectral equivalence results for constant viscosity [Elman et al., 2005]. To invert the resulting blockdiagonal preconditioner, one $\mathrm{V}$-cycle of an algebraic multigrid (AMG) solver is used for the viscous block $A$, for which we rely on the parallel smoothed aggregation code ML [Gee et al., 2006]. See Burstedde et al. [2009] for more details on the parallel Stokes solver.

[15] A nonlinear rheology requires additional iterations over the viscosity and velocity until convergence is achieved, which is measured by the change in the $L_{2}$ norm of the velocity from iteration $i-1$ to $i$ :

$$
c=\frac{\left\|\mathbf{v}_{i}-\mathbf{v}_{i-1}\right\|_{2}}{\left\|\mathbf{v}_{i}\right\|_{2}}<c_{\text {convergence }} .
$$

The velocity determines the strain rate used in the viscosity computation. This viscosity is then used to compute the solution to the Stokes problem in equation (2) with velocity as an outcome. To initialize the nonlinear iterations, a uniform strain rate of $10^{-16} \mathrm{~s}^{-1}$ is used, an order of magnitude smaller than the transition strain rate between diffusion and dislocation creep, so that the first estimate occurs entirely in the diffusion creep regime [Hirth and Kohlstedt, 2003].

\subsection{Model}

[16] The global models require as input a buoyancy field in the form of temperature, and plate boundaries represented by narrow weak zones. The temperature field consists of several parts: the lithosphere, subducting slabs in the upper mantle, and lower mantle structure. The lithospheric thickness is derived from a half-space cooling model using the lithospheric age [e.g., Schubert et al., 2001]:

$$
T_{L}(z, \tau)=T_{s}+\left(T_{m}-T_{s}\right) \operatorname{erf}\left(\frac{z}{2 \sqrt{\kappa \tau}}\right)
$$

where $T_{s}$ and $T_{m}$ are the surface and mantle temperatures, $\kappa$ is the thermal diffusivity, $\tau$ the age of the lithosphere, and $z$ is depth. The age of the oceanic lithosphere is determined from a map of lithospheric plate age [Müller et al., 2008]. Within areas not purely oceanic, three types of crust are defined: cratons with an age of $300 \mathrm{Ma}$ [Stoddard and Abbott, 1996; Spasojevic et al., 2010], areas within a distance of $\sim 750 \mathrm{~km}$ to (recent) subduction zones with an age of $75 \mathrm{Ma}$, and remaining areas with an age of $125 \mathrm{Ma}$ [Stadler et al., 2010].

[17] Slabs need to be well resolved so that they have the option of acting as stress guides [Zhong et al., 1998]. The use of global tomography models is avoided in the upper mantle, because they are almost always smoother than what one would expect from thermal models of subduction. Where high resolution tomography exists, they are consistent with thermal models [Schmandt and Humphreys, 2010]. Because such high resolutions do not exist globally, a thermal model of upper mantle slabs is based on smooth slab contours defined by seismicity based on the RUM model [Gudmundsson and Sambridge, 1998], and a local age based on lithospheric age at the trench just before the plate subducts. Using cubic splines, these smooth contours are extrapolated to the radial coordinates of the finite element mesh used for the input model. A thermal age for these slab contours is obtained from the age grid of the oceanic lithosphere [Müller et al., 2008], and thickness of the effective lithosphere taken from the half space thermal mode (equation (8)). Using GMT routines [Wessel and Smith, 1991], this thermal field is smoothed onto a uniform raster file and then resampled on the initial finite element mesh.

[18] The lower mantle low temperature structures are derived from the S20RTS tomography model [Ritsema et al., 2004], a seismic S-wave model using both body and surface waves. The tomography model is scaled into nondimensional temperature anomalies using $\delta T=-\omega \delta V_{s}$, with the scaling factor $\omega$ varied for different models within the range [0.0, 0.25] [Karato and Karki, 2001; Forte, 2007]. The lithosphere and upper mantle models and the upper and lower mantle models are blended at $75 \mathrm{~km}$ and $650 \mathrm{~km}$ depths, respectively, over a length scale of $75 \mathrm{~km}$.

[19] The surface positions of convergent plate margins and mid-ocean ridges are derived from a compilation of Bird [2003]. To incorporate the trenches, fracture zones, and ridges in our models, the line data is propagated downward from the surface using specified dip angles in a preprocessing step. For converging plate boundaries, a surface is created with a dip angle starting at $0 \mathrm{~km}$ depth $\left(\theta_{o}\right)$ which transitions to a second dip angle $\left(\theta_{i}\right)$ at a depth $\left(z_{i}\right)$. The parameters $\theta_{o}, \theta_{i}$, and $z_{i}$ can all vary along strike, and are obtained for thrust events with $M_{w} \geq 5.5$ using the hypocenters and dip angles of CMT solutions [Dziewonski and Anderson, 1981] over a 32 year period (Global CMT Project, available at http://www. globalcmt.org/, accessed September 2009). Point clouds describing the resulting surfaces are imported into our finite element implementation, where a viscosity reduction factor is computed based on the distance along outward normal vectors to these fault surfaces. This factor $\Gamma(\mathbf{x})$, which multiplies the viscosity (see below), is derived as

$$
\begin{aligned}
\Gamma(\mathbf{x}) & =1-(1-w) \exp \left(-\frac{x_{1}^{2}}{2 a^{2}}\right) \\
\text { with } x_{1} & =\max (0, x-a),
\end{aligned}
$$


Table 2. Parameters Used in the Viscosity Law for the Reference Model

\begin{tabular}{|c|c|c|c|c|}
\hline Parameter & Symbol & $\begin{array}{c}\text { Upper Mantle } \\
\text { Dislocation Creep }\end{array}$ & $\begin{array}{c}\text { Upper Mantle } \\
\text { Diffusion Creep }\end{array}$ & $\begin{array}{c}\text { Lower Mantle } \\
\text { Diffusion Creep }\end{array}$ \\
\hline Grain size & $d$ & - & $10 \times 10^{3} \mu \mathrm{m}$ & $93 \times 10^{3} \mu \mathrm{m}$ \\
\hline Grain size exponent & $p$ & - & 3.0 & 3.0 \\
\hline Pre-exponent & $A$ & $9 \times 10^{-20}$ & 1.0 & 1.0 \\
\hline Water content & $C_{\mathrm{OH}}$ & $10^{3} \mathrm{ppm}$ & $10^{3} \mathrm{ppm}$ & $10^{3} \mathrm{ppm}$ \\
\hline Water content exponent & $r$ & 1.2 & 1.0 & 1.0 \\
\hline Stress exponent & $n$ & $3.0^{\mathrm{a}}$ & 1.0 & 1.0 \\
\hline Activation energy & $E_{a}$ & $480 \times 10^{3} \mathrm{~J} / \mathrm{mol}$ & $335 \times 10^{3} \mathrm{~J} / \mathrm{mol}$ & $335 \times 10^{3} \mathrm{~J} / \mathrm{mol}$ \\
\hline Activation volume & $V_{a}$ & $11 \times 10^{-6} \mathrm{~m}^{3} / \mathrm{mol}$ & $2 \times 10^{-6} \mathrm{~m}^{3} / \mathrm{mol}$ & $1.25 \times 10^{-6} \mathrm{~m}^{3} / \mathrm{mol}$ \\
\hline Yield temperature & $T_{y}$ & $1073 \mathrm{~K}$ & $1073 \mathrm{~K}$ & $1073 \mathrm{~K}$ \\
\hline Surface yield stress & $\sigma_{o}$ & $0.1 \mathrm{MPa}$ & $0.1 \mathrm{MPa}$ & $0.1 \mathrm{MPa}$ \\
\hline Yield stress gradient & $\delta \sigma / \delta z$ & $15 \mathrm{MPa} / \mathrm{km}$ & $15 \mathrm{MPa} / \mathrm{km}$ & $15 \mathrm{MPa} / \mathrm{km}$ \\
\hline Maximum yield stress & $\sigma_{y}^{\max }$ & $100 \mathrm{MPa}^{\mathrm{a}}$ & $100 \mathrm{MPa}^{\mathrm{a}}$ & $100 \mathrm{MPa}^{\mathrm{a}}$ \\
\hline
\end{tabular}

${ }^{\text {a}}$ Denotes values varied in this study.

where $x$ denotes a point's normal distance to the trench or ridge surface, $a$ the half-width of the weak zone, and $w$ the prefactor for the viscosity. Nominally, $a=5 \mathrm{~km}$ and $w=10^{-5}$ are used, resulting in Gaussian smoothed zones with a width of about $10 \mathrm{~km}$, in which the viscosity is reduced by five orders of magnitude. The weak zones extend deeper into the mantle than seismogenic zones in order to mimic the effect of viscosity reduction associated with the release of water into the mantle wedge [Hebert et al., 2009]. Only the boundary between the Nazca and South America plates around Peru has a higher viscosity with $w=5 \times 10^{-3}$. The Peru-Chile trench region has seen several large earthquakes with magnitudes larger than 8.0 and is in a strong compressional regime [Isacks and Molnar, 1971; Uyeda and Kanamori, 1979; Jarrard, 1986], which points to significant coupling between the overriding and subducting plates. Increasing the weak zone factor locally from $10^{-5}$ to $5 \times 10^{-3}$ significantly improved plate motion fits for the Nazca plate [Stadler et al., 2010].

[20] The rheology is a composite of linear (Newtonian) and nonlinear (non-Newtonian) viscosity, combined with a yielding law [Billen and Hirth, 2007]. The dominant mechanism in the upper mantle is the nonlinear dislocation creep $(d s)$, and in the lower mantle the linear diffusion creep $(d f)$. We use a general viscosity law from Hirth and Kohlstedt [2003]:

$$
\eta_{d f, d s}=\left(\frac{d^{p}}{A C_{\mathrm{OH}}^{r}}\right)^{\frac{1}{n}} \dot{\varepsilon}^{\frac{1-n}{n}} \exp \left(\frac{E_{a}+P V_{a}}{n R T}\right),
$$

where $\eta$ is viscosity in $\mathrm{Pa} \mathrm{s}, d$ grain size in $\mu \mathrm{m}, C_{\mathrm{OH}}$ water content in parts per million of silicon, and $n$ is the stress exponent. $\dot{\varepsilon}_{\mathrm{II}}$ is the second invariant of the strain rate tensor in $\mathrm{s}^{-1}$ :

$$
\dot{\varepsilon}_{\mathrm{II}}=\left[\frac{1}{2} \sum_{i j} \dot{\varepsilon}_{i j} \dot{\varepsilon}_{i j}\right]^{\frac{1}{2}}
$$

$E_{a}$ is the activation energy in $\mathrm{J} / \mathrm{mol}, P$ lithostatic pressure in $\mathrm{Pa}, V_{a}$ activation volume in $\mathrm{m}^{3} / \mathrm{mol}$, and $R$ the gas constant. The temperature $T$ is defined as:

$$
T=T_{s}+T_{a d}+T_{l} \Delta T
$$

where $T_{s}$ is the surface temperature, $T_{l}$ the nondimensional local ambient temperature, and $T_{a d}$ the adiabatic temperature. The parameters $A, n, r$ and $p$ are determined experimentally [Hirth and Kohlstedt, 2003]. The composite viscosity is obtained by combining the viscosity from diffusion creep $\left(\eta_{d f}\right)$ and viscosity from dislocation creep $\left(\eta_{d s}\right)$ using a harmonic mean. Along with a yield criterion with yield strength $\sigma_{y}$, we obtain an effective viscosity:

$$
\begin{gathered}
\eta_{\text {comp }}=\frac{\eta_{d f} \eta_{d s}}{\eta_{d f}+\eta_{d s}}, \\
\sigma_{y}=\min \left(\sigma_{o}+\frac{\delta \sigma}{\delta z} z, \sigma_{y}^{\max }\right), \\
\eta_{\text {eff }}=\Gamma(\mathbf{x}) \min \left(\frac{\sigma_{y}}{\dot{\varepsilon}_{\mathrm{II}}}, \eta_{\text {comp }}\right) .
\end{gathered}
$$

The yielding law is only applied if the local temperature is lower than the yield temperature $T_{y} . \Gamma(\mathbf{x})$ is the reduction factor used to define weak zones, as described in equation (9). The stress exponent $n$ in equation (10) determines the nonlinearity of the system, and hence has a substantial impact on the model outcome. The maximum yield stress $\sigma_{y}^{\max }$ is also an essential parameter in the global models, because it determines the strength of plates and slabs. Both of these parameters, $n$ and $\sigma_{y}$, are varied in this study. In Table 2, we provide further explanation and associated numerical values of the parameters in the constitutive equations.

\subsection{Model Analysis}

[21] Several quantities are used to analyze and compare global models with each other: plate velocities, net surface rotation, plateness, and strain rates and state of stress in plates and slabs. The velocities at the surface are compared to the NNR_NUVEL1A plate motion model in the no-netrotation (NNR) reference frame [DeMets et al., 1994], and to the HS3_NUVEL1A model in the hot spot reference frame [Gripp and Gordon, 2002]. We also compared the motions of the main plates predicted by these plate motion models to the NNR_MORVEL56 model [Argus et al., 2011], and found that differences with the earlier kinematic models with 
no net rotation are significantly smaller than the differences with the outcomes of the numerical models. Comparison to the NNR_NUVEL1A is accomplished by removing the net surface rotation from the surface velocity field. The net rotation is computed from the surface velocities as follows [Torsvik et al., 2010]:

$$
\omega_{n e t}=\frac{3}{8 \pi r^{4}} \sum_{i} \int_{S}\left(\omega_{i} \times \mathbf{r}\right) \times \mathbf{r} d s_{i},
$$

where $\mathbf{r}$ is the position vector, $\omega_{i}$ the rotation rate vector of plate $i, \int_{S} \ldots d s$ the integration over the entire sphere, $\int_{S} \ldots d s_{i}$ the integration over the area of plate $i$, and $\Sigma_{i}$ the summation over all plates. The net surface rotation of the numerical models can be compared to estimates derived from paleo plate motion data and to previous modeling studies [Becker, 2006; Conrad and Behn, 2010; Torsvik et al., 2010]. Surface velocities are also compared to the HS3_NUVEL1A hot spot reference frame model, which requires the lower mantle rotation instead of the net surface rotation be removed from surface velocities.

[22] For each plate, the misfit $\alpha$ of the velocity direction with respect to a particular plate model is computed, and integrated over the plate:

$$
\alpha=\frac{1}{S} \int_{S} \sin ^{-1} \frac{\left\|\mathbf{v}_{r} \times \mathbf{v}_{a}\right\|}{\left\|\mathbf{v}_{r}\right\|\left\|\mathbf{v}_{a}\right\|} d s,
$$

where $\mathbf{v}_{r}$ is the surface velocity resulting from the numerical model, and $\mathbf{v}_{a}$ the actual velocity described by the plate motion model within the domain (plate polygon) $S$. Similarly, the plate velocity magnitude misfit $m$ is computed as the ratio between the averaged plate velocity in the numerical model and the average velocity in the plate according to the plate motion model:

$$
m=\frac{\frac{1}{S} \int_{S}\left\|\mathbf{v}_{r}\right\| d s}{\frac{1}{S} \int_{S}\left\|\mathbf{v}_{a}\right\| d s} .
$$

Additionally, we use two different measures of plateness, indicating how well a plate behaves like a rigid block with deformation only at the boundaries. This is expressed in how much the plate moves according to one rotation pole, in two different ways:

$$
\begin{gathered}
P_{1}=\frac{1}{S} \int_{S} \frac{\left|\mathbf{v}_{r} \cdot \mathbf{v}_{b f}\right|}{\left\|\mathbf{v}_{r}\right\|\left\|\mathbf{v}_{b f}\right\|} d s, \\
P_{2}=1-\frac{1}{S} \int_{S} \frac{\left\|\mathbf{v}_{r}-\mathbf{v}_{b f}\right\|}{\left\|\mathbf{v}_{r}\right\|} d s,
\end{gathered}
$$

where $\mathbf{v}_{r}$ is the surface velocity resulting from the numerical model, and $\mathbf{v}_{b f}$ is the surface velocity from the best fitting Euler pole (i.e., the pole which best fits all the computed velocities) within the domain $S$. $\|\cdot\|$ denotes the Euclidean norm and thus $\left\|\mathbf{v}_{r}-\mathbf{v}_{b f}\right\|$ is the root mean square (RMS) difference. A plateness of 1 implies that the plate is moving entirely with one rotation pole, and hence is a 'perfect' plate. However, the Earth does not have perfect plateness for all plates as there is diffuse deformation in the interior of some plates, such as the Indian plate [e.g., Gordon, 1998]. Plateness $P_{1}$ is a measure of how well aligned the local velocity is to the velocity resulting from a single rotation pole. $P_{2}$ also takes into account magnitude differences between the local velocity and the best fitting pole velocity. Other plateness measures have been proposed that describe the distribution of deformation defined by the root mean squared velocity with respect to an average velocity [Zhong et al., 1998], or by the second invariant of the surface strain rate [Tackley, 2000].

[23] Changes in rheology and temperature scaling of lower mantle anomalies can have an important effect on the bulk viscosity in the numerical models. Because the rheology is nonlinear, this effect cannot be predicted a priori. Therefore, we compute averaged viscosities of the upper and lower mantle to determine how the stress exponent, yield stress, and lower mantle tomography scaling affect the bulk viscosity [Parmentier et al., 1976; Christensen, 1984]:

$$
\langle\langle\eta\rangle\rangle=\frac{\int_{V} \eta \dot{\varepsilon}_{\mathrm{II}}^{2} d V}{\int_{V} \dot{\varepsilon}_{\mathrm{II}}^{2} d V},
$$

where $\eta$ is the actual local viscosity, $\dot{\varepsilon}_{\mathrm{II}}$ the second invariant of the strain rate, and $V$ denotes the volume over which the viscosity is averaged.

[24] The strain rates and state of stress within plates and subducting slabs are also determined. The surface strain rates are compared to the Global Strain Rate Mapping Project (GSRMP) model from Kreemer et al. [2003]. This strain rate model is derived from GPS velocities, Quaternary fault slip rates, and focal mechanisms of shallow earthquakes. The strain rate in the shallow and deeper slabs are also compared to minimum average slab strain rate constraints, based on minimum seismic moment estimates from seismicity in the period 1904-1974 [Bevis, 1988], 1977-1992 [Holt, 1995], or 1977-1994 [Nothard et al., 1996].

[25] The state of stress in plates and slabs resulting from the numerical models is studied by decomposing the stress tensor in its principal components, where the first and third eigenvectors correspond to the tensional and compressional axes, respectively. The stress regime in overriding plates can then be compared to observed regimes [Jarrard, 1986; Lallemand et al., 2005]. These studies characterize the regimes using stress and strain indicators such as focal mechanisms, Quaternary faults and folds, volcanic vent alignments, overcoring, and the presence of back-arc spreading. In the subducting slabs, the state of stress is compared to stress orientations determined from focal mechanisms [Isacks and Molnar, 1971; Alpert et al., 2010]. Also individual centroid moment tensor (CMT) stress axes are used to test the model stress in subducting slabs by interpolating the model stress field onto the CMT locations.

[26] Finally, we assess the models using the entire suite of constraints available to us: global and regional plate motions, plateness, net rotation, strain rates, and the state of stress in plates and slabs. The models are then scored, permitting us to 
Table 3. Varied Global Rheology Parameters

\begin{tabular}{lcccc}
\hline Model & Case & $\begin{array}{c}\text { Yield Stress } \\
\sigma_{y}\end{array}$ & $\begin{array}{c}\text { Stress Exponent } \\
n\end{array}$ & $\begin{array}{c}\text { LM Tomography } \\
\text { Scaling } \omega\end{array}$ \\
\hline run97 & 1 & $50 \mathrm{MPa}$ & 3.0 & 0.1 \\
run104 & 2 & $100 \mathrm{MPa}$ & 3.0 & 0.1 \\
run98 & 3 & $200 \mathrm{MPa}$ & 3.0 & 0.1 \\
run99 & 4 & $400 \mathrm{MPa}$ & 3.0 & 0.1 \\
run107 & 5 & $800 \mathrm{MPa}$ & 3.0 & 0.1 \\
run100 & 6 & $100 \mathrm{MPa}$ & 2.0 & 0.1 \\
run102 & 7 & $100 \mathrm{MPa}$ & 3.25 & 0.1 \\
run101 & 8 & $100 \mathrm{MPa}$ & 3.5 & 0.1 \\
run105 & 9 & $400 \mathrm{MPa}$ & 3.5 & 0.1 \\
run106 & 10 & $800 \mathrm{MPa}$ & 3.5 & 0.1 \\
run108 & 11 & $1200 \mathrm{MPa}$ & 3.5 & 0.1 \\
run109 & 12 & $1200 \mathrm{MPa}$ & 3.75 & 0.1 \\
run110 & 13 & $100 \mathrm{MPa}$ & 3.0 & 0.0 \\
run94 & 14 & $100 \mathrm{MPa}$ & 3.0 & 0.25 \\
& & & &
\end{tabular}

judge which combinations of yield stress and stress exponent best fit this set of constraints.

\section{Results}

\subsection{Introduction}

[27] We have computed a set of global instantaneous models of mantle convection with plates, with the goal to discern effects of rheology on plate motions, plateness, strain rates, state of stress, and slab dynamics. The nonlinearity of the upper mantle rheology, in the form of the stress exponent $n$, is varied between 2 and 3.75, ranging below and above the experimentally accepted range, [3, 3.5] [Karato and Wu, 1993; Hirth and Kohlstedt, 2003] (Table 3). The strength of plates and slabs represented by the yield stress $\sigma_{y}$ is chosen in a range between $50 \mathrm{MPa}$ and $1200 \mathrm{MPa}$, such that it covers the values based on laboratory studies and geodynamic models [Ranalli, 1995; Kohlstedt et al., 1995; Billen and Hirth, 2007]. Finally, the scaling between the seismic velocity anomalies in tomography inversions to temperature anomalies $\omega$ is varied between 0 (no lower mantle structure) to 0.25 [Karato and Karki, 2001; Forte, 2007]. Outcomes of these models are interior and surface flow velocities, state of stress, strain rate, and viscosity.

[28] A set of 14 cross-sections in 6 regions is selected for detailed study (Figure 1). These regions (the Aleutians, Japan, Marianas, Tonga, Scotia, and South America areas) were selected because they represent subduction zones spanning regions with fundamentally different coupling between plates [Uyeda and Kanamori, 1979]. Several of these regions display complex plate motions and microplate kinematics with and without trench rollback (Tonga, Marianas, Scotia). This degree of complexity in plate boundaries is present in our models, and hence the microplate behavior provides excellent model tests. Studying such a large set of cross-sections and areas in detail allows us to consider a wide range of slab and plate geometries with respect to variation in input properties.

[29] A typical viscosity field resulting from a numerical model shows the resulting broad-scale variations in viscosity, zones of yielding, as well as the imposed 'faults' (Figure 2). Narrow low-viscosity features with a value of $10^{18} \mathrm{~Pa}$ s are the weak zones defining plate boundaries. The weak zones in subduction zones have a dip that varies both laterally and

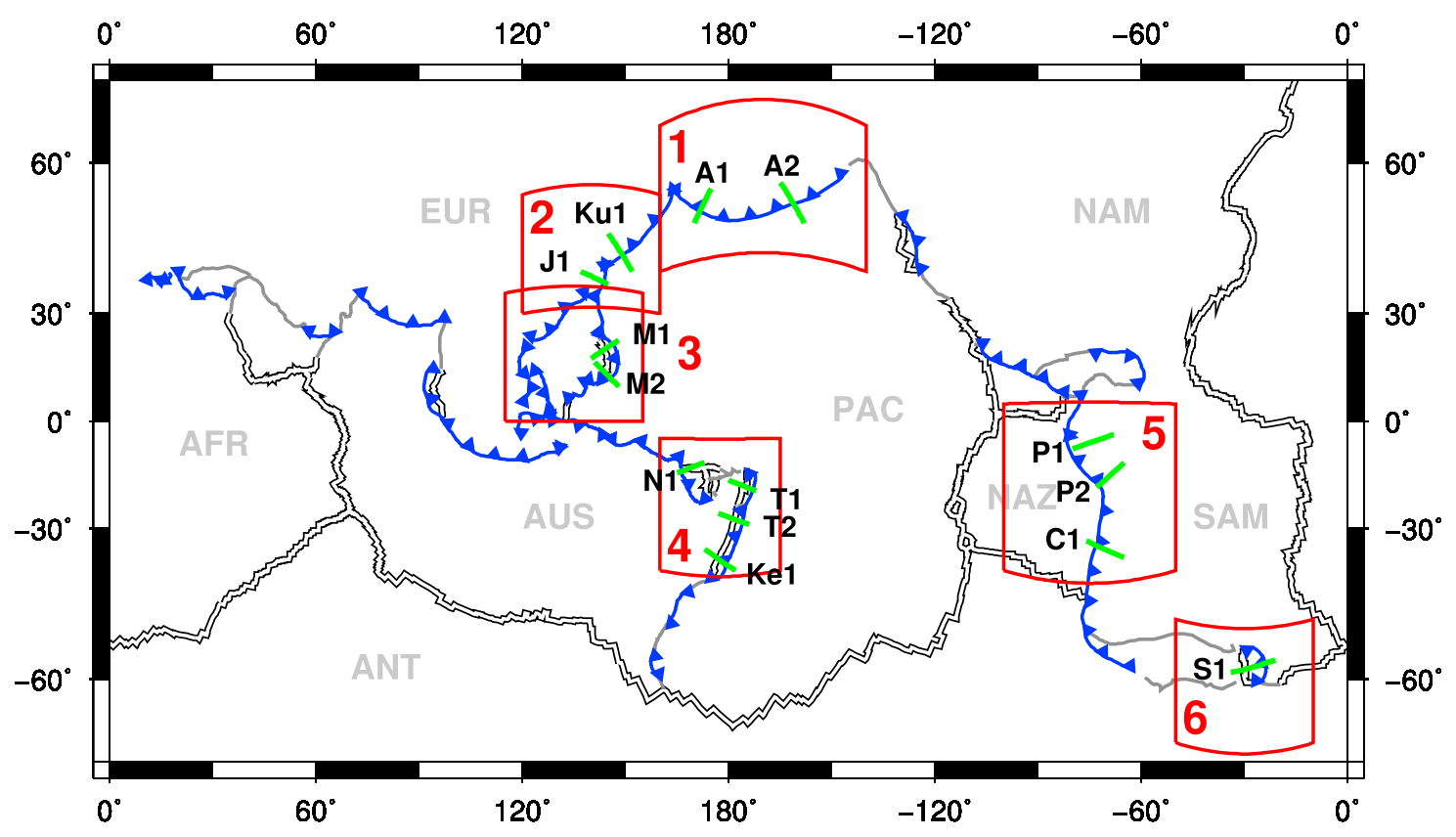

Figure 1. Map of regions and cross-sections selected for detailed analysis. Cross-section labels: A: Aleutians; C: Chile; J: Japan; Ke: Kermadec; Ku: Kurile; M: Marianas; N: New Hebrides; P: Peru; S: Sandwich; T: Tonga. Region labels: 1: Aleutians; 2: Japan; 3: Marianas; 4: Tonga; 5: South America; 6: Scotia. Plate labels: AFR: Africa; ANT: Antarctica; AUS: Australia; EUR: Eurasia; NAM: North America; NAZ: Nazca; PAC: Pacific; SAM: South America. 




(b)

(c)
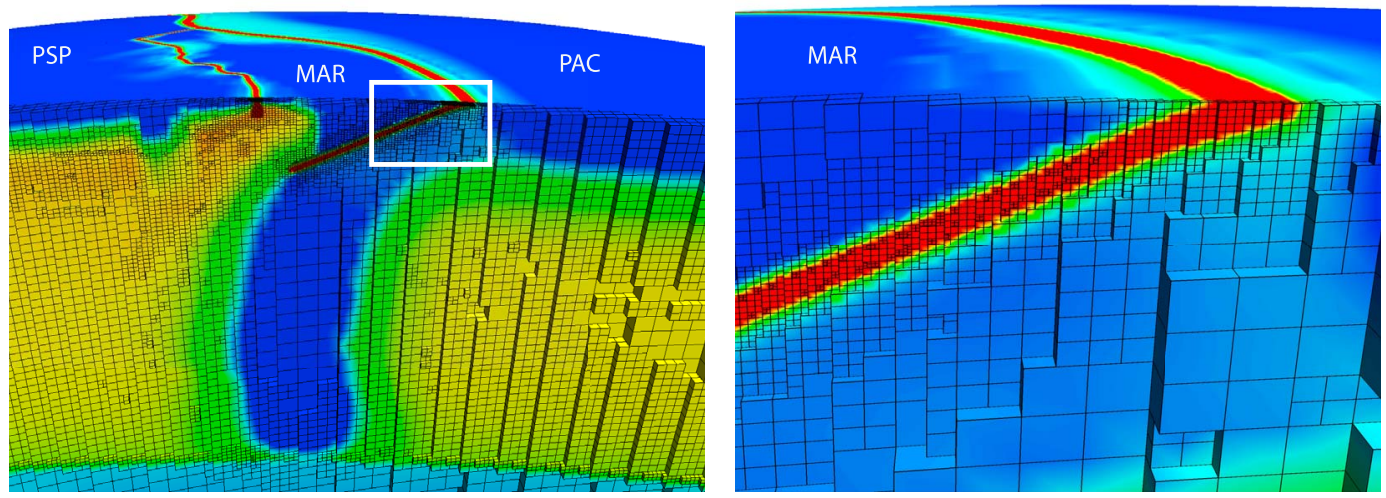

Figure 2. (a) Cutout showing viscosity in a global model with stress exponent $n=3.0$ and yield stress $\sigma_{y}=100 \mathrm{MPa}$ (Case 2) through the Marianas and Philippines. (b) Zoom-in on viscosity of the Marianas subduction zone, showing the mesh. (c) Further zoom-in on the hinge of the Marianas slab, as denoted by the white box in Figure 2b. Plate labels are: EUR: Eurasia; MAR: Marianas; PAC: Pacific; PSP: Philippine Sea.

with depth, while those at ridges and fracture zones are vertical (Figure $2 b$ ). The viscosity in plate interiors is predominantly governed by the maximum cutoff value of $10^{24} \mathrm{~Pa}$ s due to low internal deformation and low intra-plate strain rates. Around plate boundaries, this results in several orders of magnitude change in viscosity over short distances, necessitating the $1 \mathrm{~km}$ resolution around weak zones (Figure 2c). This refinement in the mesh is facilitated through the viscosity gradient term in the error estimator (equation (3)), and occurs during the iterative solution of the Stokes equation. Elsewhere in the plates and slabs, the resolution is 2-10 km. In the upper mantle, the cold and therefore stiff slabs are defined by sharp gradients in viscosity and temperature with respect to the surrounding upper mantle with lower viscosity. The longer wavelength structures in the lower mantle have much smoother gradients, being derived from a smooth tomography model. Here the resolution is on the order of $80-150 \mathrm{~km}$. In addition, the effect of nonlinearity on the upper mantle viscosity is evident in mantle wedges: the high velocity corner flow causes strain rates to be high, giving rise to a low viscosity governed by dislocation creep. The effect of strain rate weakening is also visible in the hinges of subducting plates, where the bending of cold plates into the mantle results in yielding.

\subsection{Plate Motions and Plateness}

\subsubsection{Global Plate Motions}

[30] Global plate motions constitute a first order test of dynamic convection models with plates, because the plate behavior is only Earth-like for a limited range of parameters in the constitutive relations. If plates are too stiff, they may move too slowly compared to observed motions, although they may satisfy plateness constraints. On the other hand, plates that are too weak may move too fast while exhibiting excessive internal deformation, as indicated through measures of plateness. Here we investigate the fine balance between these end member scenarios.

[31] In general, the global plate motion directions match the NNR_NUVEL1A plate motion model well [DeMets et al., 1994], but the velocity magnitudes are a strong function of the rheology. An increase in yield stress from 100 (Case 2, Figure 3a) to $800 \mathrm{MPa}$ (Case 5, Figure $3 \mathrm{~b}$ ) results in a decrease in magnitude of the predicted model velocity in both subducting and overriding plates, while generally not significantly altering the directions of plate motions. This velocity 
(a)

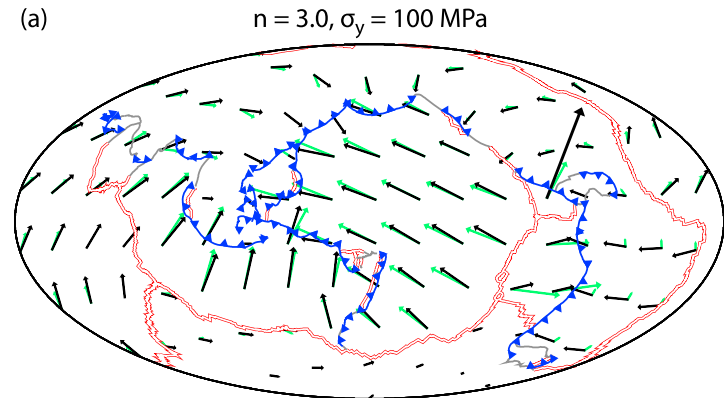

(b)

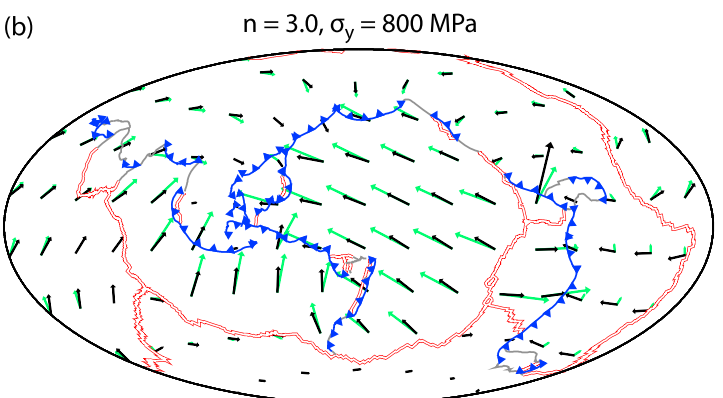

(d)

(c)



$\mathrm{n}=3.75, \sigma_{\mathrm{y}}=1200 \mathrm{MPa}$

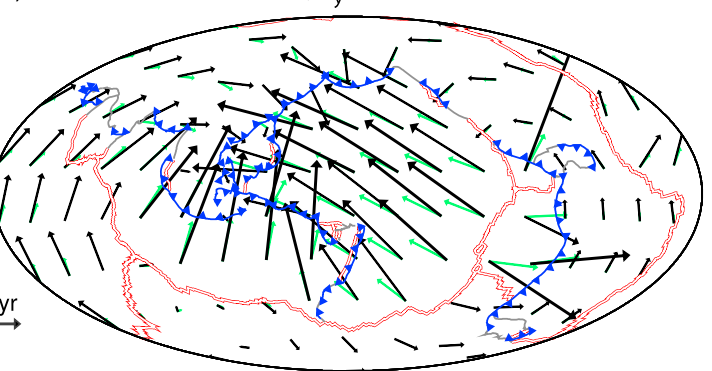

Figure 3. Global plate motions with variation of yield stress and stress exponent. Known plate motions in a no-net-rotation frame (NNR_NUVEL1A) in green are compared against modeled plate motions in black. (a) Case 2: $\sigma_{y}=100 \mathrm{MPa}$ and $n=3.0$; (b) Case 5: $\sigma_{y}=800 \mathrm{MPa}, n=3.0$; (c) Case 10: $\sigma_{y}=800 \mathrm{MPa}, n=3.5$; (d) Case 12: $\sigma_{y}=1200 \mathrm{MPa}, n=3.75$.

reduction is strongest in the subducting plates (Pacific, Australia, Cocos), as the increase in yield stress allows for less yielding in the slab hinges, limiting the ability of the plate to subduct. An increase in stress exponent from 3.0 to 3.5, while the yield stress remains constant at $800 \mathrm{MPa}$ (Case 10), results in a significant speedup of all plates due to stronger strain rate weakening in the upper mantle and hence lower viscosity below the plates and in the hinge zones (compare Figure $3 \mathrm{~b}$ to Figure 3c). A further increase in stress exponent from 3.5 to 3.75 even as the yield stress increases from 800 to $1200 \mathrm{MPa}$ (Case 12, Figure 3d) causes the plates to further speed up. Evidently, the weakening induced by the increase of the stress exponent overwhelms the strengthening caused by the increase in yield stress. Now, with the larger stress exponent and yield stress, significant changes in plate motion direction can be seen for the Nazca and South America plates (compare Figure $3 \mathrm{c}$ to Figure $3 \mathrm{~d}$ ). It could be argued that the plate motions in the South America region experience more effect from changes in yield stress and stress exponent than elsewhere, due to the stronger plate boundary coupling around Peru.

[32] The sensitivity of plate motion direction and speed to the stress exponent and yield stress is explored for several plates and for a global average. The angle misfit, $\alpha$, is defined as the average clockwise angle between the model plate velocity and the NNR NUVEL1A velocity (equation (17)); a value of 0 denotes a perfect angle fit. The normalized velocity is the average plate speed divided by the NNR_NUVEL1A speed (equation (18)); a value of 1 indicates a plate moving at the correct speed. The global average is a surface-weighted average of the nine largest plates (AFR, ANT, AUS, EUR, IND, NAM, NAZ, PAC, SAM). The global averaged angle misfit is the average of absolute misfit values. It is noteworthy that the best angle fit occurs for different combinations of the stress exponent and yield stress for different plates (Figures $4 a-4 c$ ), suggesting that the misfits are governed by regional characteristics such as geometry and interplate coupling, rather than rheology. In contrast, the sensitivity of the normalized velocity magnitude to variations in parameters is consistent between each plate and the global average (Figures $4 \mathrm{~d}-4 \mathrm{f}$ ). There is a significant dependence on the stress exponent for all yield stresses used, indicating that nonlinear strain rate weakening is dominant in determining plate speeds. The strain rate weakening occurs in the hinge of the subducting slab (Figure 2), influencing the ease with which the slab subducts. It also occurs in the asthenosphere, governing the amount of decoupling between the plates and underlying mantle. The strong sensitivity of plate speeds to rheology provides us with combinations of stress exponent and yield stress that result in acceptable plate motions, mostly with a stress exponent between 3 and 3.25. Only models with weaker plates and slabs (i.e. with a yield stress below a threshold of around $200 \mathrm{MPa}$ ) display dependence on yield stress, and require significantly lower stress exponents.

[33] There are two domains in the space of yield stress $\left(\sigma_{y}\right)$ and stress exponent $(n)$ evident in Figure 4 (and subsequent similar representations) which we illustrate with a schematic (Figure 5). In domain I, both the yield stress and the stress exponent have a strong influence on the resultant quantity, e.g., plate velocity magnitude. This behavior is observed consistently below a yield stress of $200 \mathrm{MPa}$. In domain II, the yield stress has little or no bearing on the result, and only the stress exponent governs the outcome. This occurs for yield stresses above $200 \mathrm{MPa}$. The transition between the two domains is governed by the convective stress $\sigma_{c}$, determined by the bulk viscosity and integrated buoyancy in the system. Yield stresses below this transition stress limit the strength of the material and hence have an effect on plate motions and 

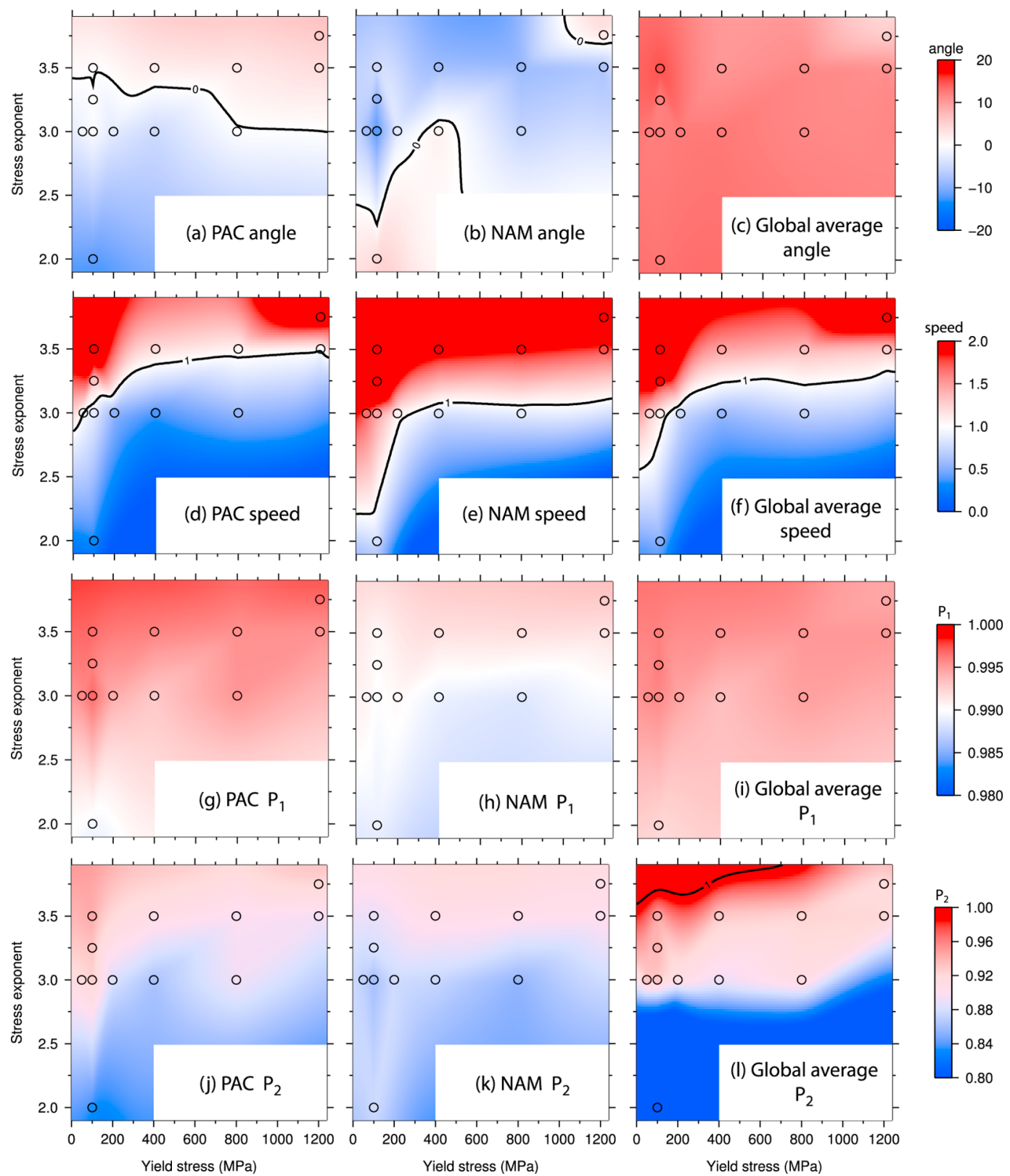

Figure 4. (a-c) Angle misfit; $(\mathrm{d}-\mathrm{f})$ plate speed normalized by observed speed; $(\mathrm{g}-\mathrm{i})$ plateness $P_{1}$; $(\mathrm{j}-\mathrm{l})$ plateness $P_{2}$. From left to right: Pacific (PAC), North America (NAM), global average weighted by surface area. The circles denote the models run in this study; the background shows the field interpolated from these values. Note that for the global average angle (Figure 4c) the absolute value of the misfit angle is used.

other resulting quantities: $\sigma_{\max }=\sigma_{y}<\sigma_{c}$. When yield stresses exceed the transition stress, the ubiquitous convective stress determines bulk ambient stresses, as mantle flow redistributes stress throughout the domain: $\sigma_{\max }=\sigma_{c}<\sigma_{y}$. Only in localized areas are the stresses higher such that the yield stress will have an effect (for example in the interior of cold slabs). There is a gradual bend in the contours with increasing yield stress, as smaller and smaller volumes contain stresses that exceed the yield stress. In both domains, gradients in the resulting quantity are stronger for larger stress exponent values (denoted by the decreased contour spacing, Figure 5), as observed for the plate motions in Figures $4 \mathrm{~d}-4 \mathrm{f}$. This illustrates the highly nonlinear response of the system to rheology.

\subsubsection{Plateness}

[34] Plateness is a measure of plate rigidity and coherence and is strongly influenced by the nonlinearity in the rheology. We use two measures of plateness. $P_{1}$ relates to the angle difference between the local plate velocity and the velocity according to the best fitting pole for the entire plate. $P_{2}$ describes the norm of the vector difference between the two velocities. An increase in yield stress (100 MPa to $800 \mathrm{MPa}$, while $n$ remains constant at 3.0; Case 2 and 5, respectively) results in smaller plateness $P_{2}$ for the Pacific 


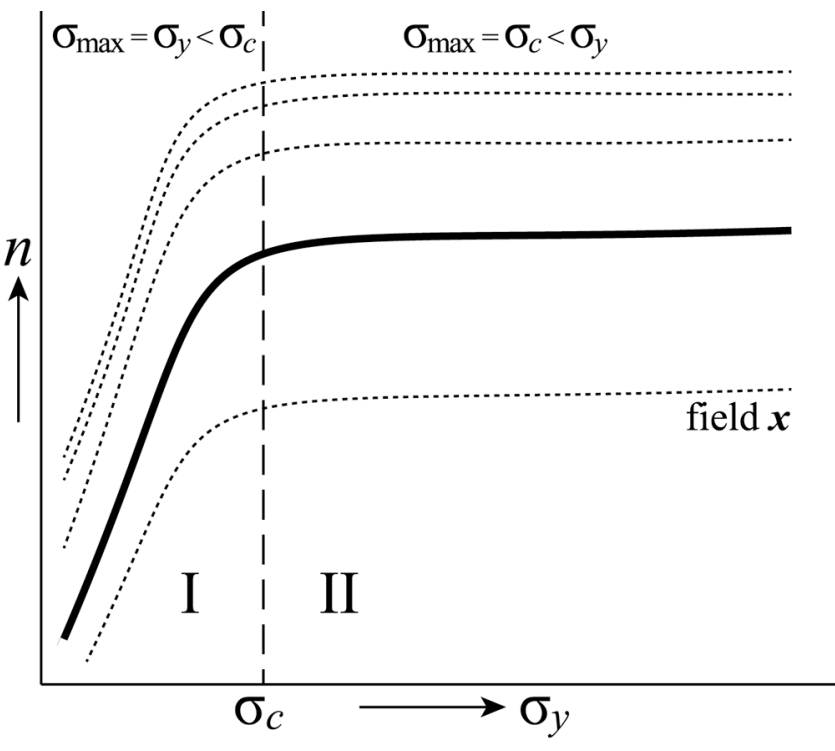

Figure 5. Schematic of the behavior of a resulting quantity as function of $\left(\sigma_{y}, n\right)$. Contour lines of the field $x$ are indicated; the two domains are denoted with I and II. The convective stress is $\sigma_{c}$.

plate, especially around the plate boundaries (Figures 6a and $6 \mathrm{~b}$ ). Also, the rotation poles for different parts of the Pacific are more broadly dispersed, indicating larger differential rotation and internal deformation. With less yielding permitted, the Pacific plate becomes more 'stuck' to the neighboring plates. Case 10 (Figure 6c) has more localized deformation with an increase in stress exponent from 3.0 to
3.5 as the yield stress remains a constant $800 \mathrm{MPa}$, as is indicated by the narrower areas with low plateness. An even higher stress exponent and yield stress allows for a stiffer plate with a high plateness (respectively 3.75 and $1200 \mathrm{MPa}$, Case 12, Figure 6d). The low $P_{2}$ areas around the plate edges have almost entirely disappeared, except for the southwest corner. Also, the Pacific plate is moving more according to a single rotation pole but with significantly higher speed than in the other models, indicated by the closer clustering and larger magnitude of the rotation poles for different sections of the plate.

[35] The integration of plateness over multiple plates allows some discrimination between model outcomes $P_{1}$ and $P_{2}$ (Figures $4 \mathrm{~g}-4 \mathrm{l}$ ). Plateness $P_{1}$ varies from plate to plate, but in general a higher stress exponent leads to a higher plateness in response to stronger localization of plate boundary deformation. The plateness decreases somewhat for higher yield stress, but this effect is much weaker than that of the stress exponent. The integrated plateness for PAC is lower than that of the global average: Presumably, the larger the plate, the more difficult it is to ensure little internal deformation and therefore high plateness. Plateness $P_{2}$ shows patterns similar to $P_{1}$. The sensitivity of $P_{2}$ to changes in rheology is larger, due to the fact that differences between the local velocity magnitude and the velocity magnitude from the best fitting pole is also taken into account, rather than just the angle difference as for $P_{1}$. Hence we found $P_{2}$ to be more diagnostic of the amount of plate deformation.

\subsubsection{Comparison to Hot Spot Reference Frame}

[36] Plate motions are compared in different reference frames, namely the no-net-rotation frame (NNR_NUVEL1A model, DeMets et al. [1994]) and the hot spot frame (a)
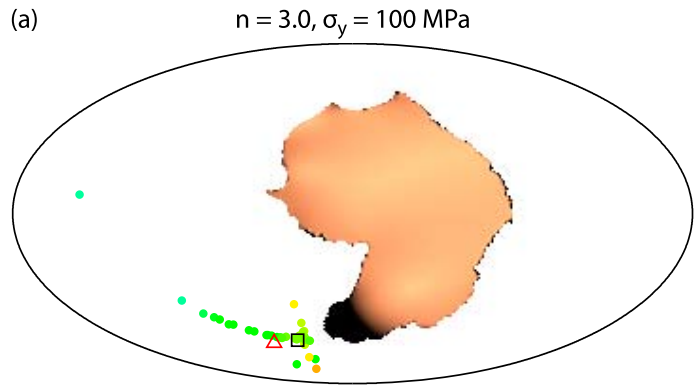

(c)

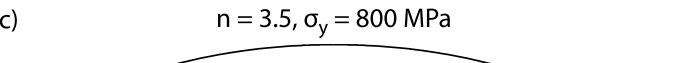

(b)

$\mathrm{n}=3.0, \sigma_{\mathrm{y}}=800 \mathrm{MPa}$

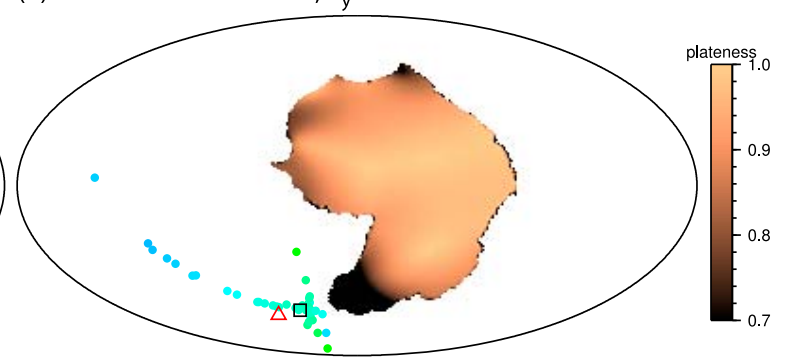

(d) $\mathrm{n}=3.75, \sigma_{\mathrm{y}}=1200 \mathrm{MPa}$

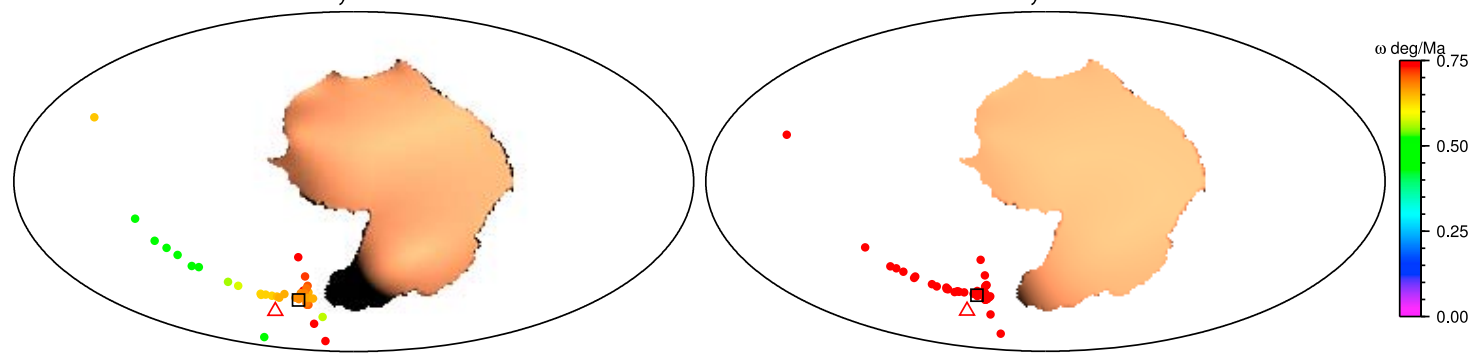

Figure 6. Pacific plateness with variation in yield stress and stress exponent. The color of the dots denotes the magnitude of the rotation pole for different plate sampling caps with a radius of $20^{\circ}$. The magnitude of the rotation pole for PAC in the NNR_NUVEL1A model is $0.64^{\circ} / \mathrm{Ma}$. Red triangle: NNR_NUVEL1A rotation pole. Black square: Rhea average rotation pole. The background color is the plateness $\bar{P}_{2}$, the RMS difference between Rhea velocities and the best fitting pole. (a) Case 2: $\sigma_{y}=100 \mathrm{MPa}$ and $n=3.0$; (b) Case 5: $\sigma_{y}=800 \mathrm{MPa}, n=3.0$; (c) Case 10: $\sigma_{y}=800 \mathrm{MPa}, n=3.5$; (d) Case 12: $\sigma_{y}=1200 \mathrm{MPa}, n=3.75$. 
(a)

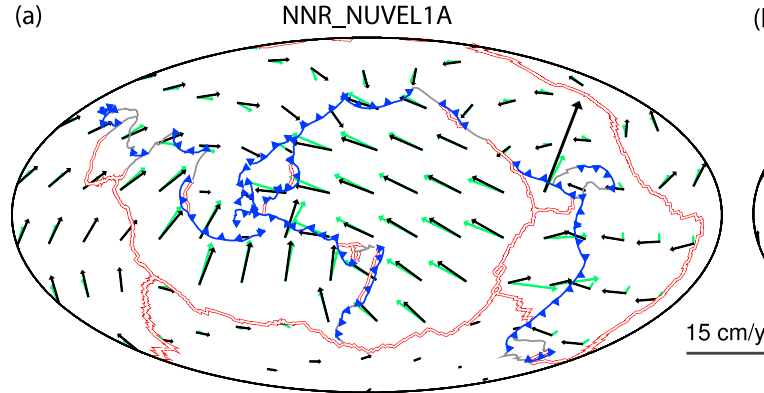

(b)

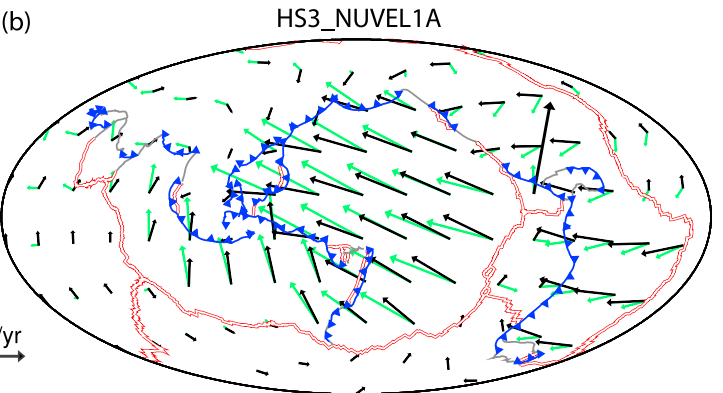

Figure 7. (a) Plate motions in NNR reference frame (black arrows), compared to NNR_NUVEL1A (green arrows), for Case 2. (b) Plate motions in hot spot reference frame (black), compared to HS3_NUVEL1A (green).

(HS3 NUVEL1A, [Gripp and Gordon, 2002]). The difference in plate motions between the two reference models in e.g., the Pacific is significant, both in direction and magnitude (Figures $7 \mathrm{a}$ and $7 \mathrm{~b}$ ); the fit of the Rhea plate motions is much worse for the HS3 NUVEL1A model than for the NNR NUVEL1A model.

[37] To assess plate motions in a hot spot reference frame, the total rotation of the lower mantle is subtracted from the surface velocity field. This lower mantle rotation is affected by the mantle bulk viscosity and by the buoyancy field present in the lower mantle, as is further explored below (section 3.2.5). Consequently, any change in lower mantle flow will result in a different surface velocity pattern in the hot spot reference frame, even if the surface velocities were to stay constant in a no-net-rotation reference frame. This makes comparisons between models with different rheology parameters more difficult, since we are assessing the combined effect of the lower mantle rotation and surface rotation. Therefore, this study mainly focuses on results in the no-net-rotation reference frame. Additionally, the platenesses $P_{1}$, and $P_{2}$ are not invariant under spherical coordinate transformations, since they are based on vector norms in a Euclidean space. These vector norms will be minimum in a no-net-rotation frame of reference, and therefore a NNR model will always yield a larger plateness than a model with non-zero net rotation such as the hot spot reference frame. This difference in plateness does not reflect a change in the amount of plate deformation, and consequently a comparison of plateness between different reference frames is not meaningful.

\subsubsection{Net Surface Rotation}

[38] The magnitude of the estimated surface net rotation varies significantly between different plate models. For instance, the HS3 model [Gripp and Gordon, 2002] has a rotation rate almost four times that of T10 [Torsvik et al., 2010], $0.44^{\circ} / \mathrm{My}$ compared to $0.13^{\circ} / \mathrm{My}$. The former is based on current-day plate motions, whereas the latter results from plate reconstructions averaged over the past $5 \mathrm{My}$. Additionally, the HS3 model uses a more restricted set of hot spots to serve as a reference frame compared to T10. Previous numerical models [Becker, 2006; Zhong, 2001; Ricard et al., 1991] typically did not contain strong net rotation, usually less than $0.15^{\circ} / \mathrm{My}$. The net rotation in the numerical models presented here shows significantly more variation than in the plate motion models described in the literature [see, e.g., Conrad and Behn, 2010, Table 1], suggesting that this quantity can be used as a constraint on rheology. One reason we show a greater range of net rotation is that we include models that do not fit plate motions well (e.g., Case 12, with $n=3.75$ and $\sigma_{y}=1200 \mathrm{MPa}$ ).

[39] The amount of net surface rotation strongly depends on the stress exponent (Figure 8). An increase in stress exponent causes all velocities in the upper mantle and plates to increase (indicated by the increase of the $L_{2}$ norm of velocity in the entire model volume), which directly influences the amount of rotation of the surface with respect to the deeper mantle. Even though the stress exponent only affects the nonlinear component of the upper mantle viscosity and therefore the bulk upper mantle viscosity (Figure 8d), the velocities in the entire domain are increased including in the lower mantle, indicating that there is a strong coupling of flow between the upper and lower mantle.

[40] The yield stress has no significant bearing on the net rotation, since it does not affect the viscosity in the mantle surrounding the slab. Only a narrow region in the $\left(\sigma_{y}, n\right)$ parameter space fits the net rotation constraint using the most recent analysis of Torsvik et al. [2010], with a stress exponent of $\sim 3.0$. The yield stress also has little effect on the bulk viscosity, especially for larger yield stresses. For both the net rotation and the bulk viscosity, we discern the same pattern in $\left(\sigma_{y}, n\right)$ space as described above (Figure 5).

\subsubsection{Lower Mantle Structure}

[41] The lateral viscosity structure of the lower mantle is a function of the conversion factor from seismic velocity to temperature anomalies, $\omega$, through the temperature dependence of the viscosity. Stronger negative temperature anomalies in the lower mantle result in structures with higher viscosities. In models with a purely depth-dependent viscosity, this additional negative buoyancy in the deep slabs would speed up plate motions [Becker and O'Connell, 2001]. This effect can be mitigated by the presence of a strong viscosity gradient across the $660 \mathrm{~km}$ phase transition, which impedes flow across the transition zone [Conrad and LithgowBertelloni, 2002]. In the nonlinear, temperature- and depthdependent models presented here, the influence of lower mantle structure strength on plate motions is not nearly as straightforward.

[42] Increasing the conversion factor from $\omega=0$ (no lateral temperature variation in the lower mantle, Case 13) to $\omega=0.1$ and to 0.25 (strong temperature anomalies in the lower mantle, Cases 2 and 14 respectively) causes a general increase in plate speeds due to the addition of negative buoyancy 



Figure 8. (a) Resulting net rotation and volume $L_{2}$ norm of velocity, color coded by stress exponent. (b) Same quantity, color coded by yield stress. (c) Net surface rotation as function of stress exponent and yield stress. (d) Integrated viscosity $\langle\langle\eta\rangle\rangle$ in the upper mantle as function of stress exponent and yield stress.

in structures with low temperature and therefore high viscosity, promoting overall flow in the mantle and plates (Figures 9b, 9e, and 9h). However, some plates slow down significantly, such as the Pacific and Australia, where slabs connect to large-wavelength anomalies of high viscosity in the lower mantle on the western side of the Pacific (Figures 9a, 9d, and 9g). Also the Nazca plate slows down, as the Nazca slab is connected to the high-viscosity structure beneath South America. Overriding plates with no attached subducting slabs, such as North and South America, Antarctica, and Africa, are only affected by the increased amount of negative buoyancy in the lower mantle, and therefore they speed up. The difference in behavior between the Nazca and South America plates is visible in the viscosity and velocity crosssections through the South America trench in Figures 9c, 9f and 9i, where Nazca on the left slows down, and South America on the right speeds up with a generally faster flow in the mantle. The Cocos and Eurasia plate speeds do not increase. The Cocos plate subducts beneath North America, but the slab does not reach the high viscosity structure in the lower mantle underneath (e.g., Figures 9a, 9d, and 9g) and is therefore not slowed down by the increase in conversion factor.

[43] The bulk lower mantle viscosity $\langle\langle\eta\rangle\rangle$ increases from $1.1 \times 10^{22}$ to $1.3 \times 10^{22}$ and to $1.7 \times 10^{22} \mathrm{~Pa} \mathrm{~s}$ for respectively the case with conversion factor $\omega=0,0.1$ and 0.25 . This partially mitigates the effect of increase in negative buoyancy on the flow, which could explain why the speedup of South America, North America and Africa from $\omega=0.0$ to 0.1 is more significant than from $\omega=0.1$ to 0.25 .

\subsection{Strain Rates}

\subsubsection{Surface Strain Rates}

[44] Surface strain rate is a manifestation of deformation of plates and their boundaries. These strain rates are directly related to the nonlinearity of the viscosity, which allows localization of deformation, visible as the narrow bands of high strain rates at plate boundaries (Figure 10). Increasing the yield stress from 100 to $800 \mathrm{MPa}$ with $n$ constant at 3.0 (Cases 2 and 5) decreases strain rates in slab hinges where yielding occurs, and in turn decreasing the velocity of both large and small plates (Figures 10a-10c compared to Figures 10d-10f). However, increasing the stress exponent from 3.0 to 3.75 has a significantly larger effect than the change in yield stress from $800 \mathrm{MPa}$ to $1200 \mathrm{MPa}$ : strain rates increase significantly throughout the plates including their boundaries (Case 12, Figures 10g-10i).

[45] Modeled output of the second invariant of the strain rate at the surface is compared to surface strain rate maps from the Global Strain Rate Mapping Project (Figures 10j101) [Kreemer et al., 2003]. A striking difference is the width and magnitude of the high strain rate areas around plate 
(a)

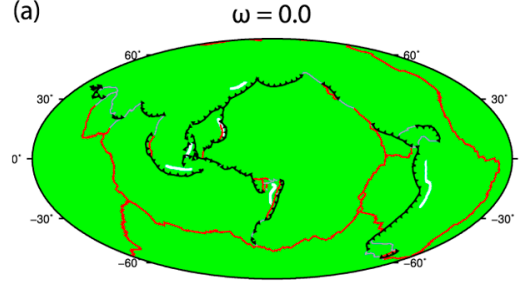

(d)

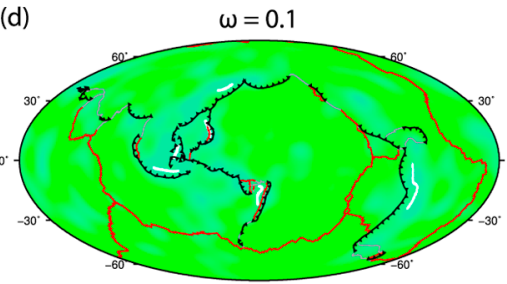

(g)

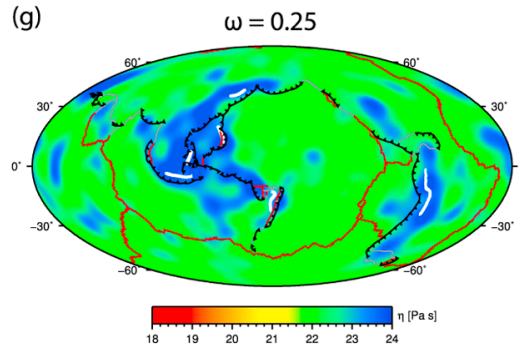

(b)
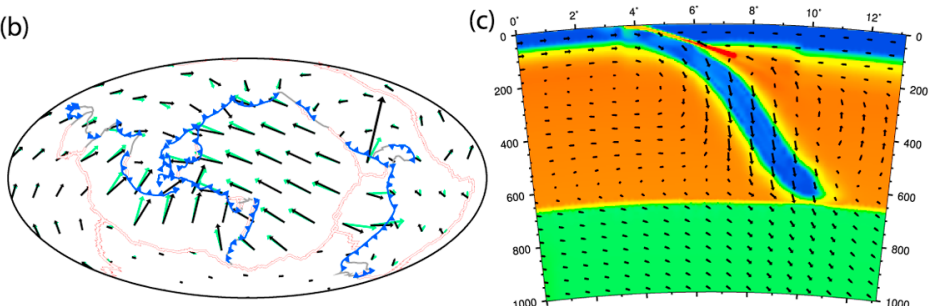

(e)


(h)



Figure 9. (a-c) Case 13, lower mantle tomography conversion factor $\omega=0.0 ;(d-f)$ Case 2 with factor $\omega=0.1$; (g-i) Case 14, factor $\omega=0.25$. (left) Viscosity field at $700 \mathrm{~km}$ depth (color map), with slab contours at $600 \mathrm{~km}$ depth plotted in white contours. The contours are defined by nondimensional temperature $T=0.55$. (middle) Global plate motions, NNR NUVEL1A plate motions are plotted in green, Rhea velocities in black. (right) Cross-sections through Peru (for location see P2, Figure 1). The background is viscosity; the vectors show velocity.

boundaries in the GSRMP maps compared with the dynamic models that have substantially narrower zones of deformation. Kreemer et al. [2003] do not include microplates in their analysis, which locally results in anomalously high strain rates in overriding plates, whereas the dynamic models have these high strain rates in the hinges of subducting plates. In the GSRMP model, the microplates are considered part of diffuse plate boundaries, increasing the length scale of deformation. The grid size of $0.6^{\circ} \times 0.5^{\circ}$ used by Kreemer et al. [2003] would only allow at most a few elements across a microplate, which is insufficient to resolve the differential velocity of the microplate with respect to the major plates. Aside from the shift from the overriding plates to subducting slab hinges, the high strain rate areas in the GSRMP maps correspond to the highest ones in the dynamic models, especially where there are sharp bends in the plate boundaries or where plate boundaries join. Examples are northern Tonga and New-Hebrides (Figure 10j) and the area north of the Marianas microplate (Figure 101). The strain rates in the Sandwich plate in the GSRMP map (Figure 10k) are significantly lower than around the other microplates. Overall plate velocities in this area are smaller than in the other regions, with slower deformation and therefore a smaller strain rate. Although our model results also indicate generally lower strain rates in this area compared to other regions, the plate boundaries themselves exhibit orders of magnitude higher strain rates than shown in the GSRMP map. This is also consistent with the averaging of strain rates over larger length scales in the GSRMP model compared to our models.

\subsubsection{Slab Strain Rates}

[46] Estimates of seismic moment release by earthquakes in slabs provide a minimum constraint on actual strain rates within slabs [Bevis, 1988]. The slabs deform at least at the rate implied by earthquakes. Any aseismic component of deformation is not represented by the earthquakes, hence these estimates give a minimum constraint on the strain rate in slabs. Shallow strain rates (between 75 and $175 \mathrm{~km}$ depth) are extracted in all studied subduction zone cross-sections (Figure 1), and compared to the minimum constraint of $10^{-15} \mathrm{~s}^{-1}$, using earthquakes between 1904 and 1974 [Bevis, 1988]. Additionally, we compare the average strain rate in the Tonga slab from $200 \mathrm{~km}$ depth downward, to the minimum estimate of $5 \times 10^{-16} \mathrm{~s}^{-1}$ [Bevis, 1988; Holt, 1995; Nothard et al., 1996].

[47] The strain rates in slabs are a function of yield stress and stress exponent (Figure 11). Strain rates in slabs increase strongly with increase in stress exponent, and decrease with yield stress only in the low yield stress regime. For yield stresses higher than about $200 \mathrm{MPa}$, only the stress exponent has a strong effect on strain rate. This pattern is similar for all cross-sections; this uniformity suggests that rheology is of much more influence on strain rate in slabs than regional 

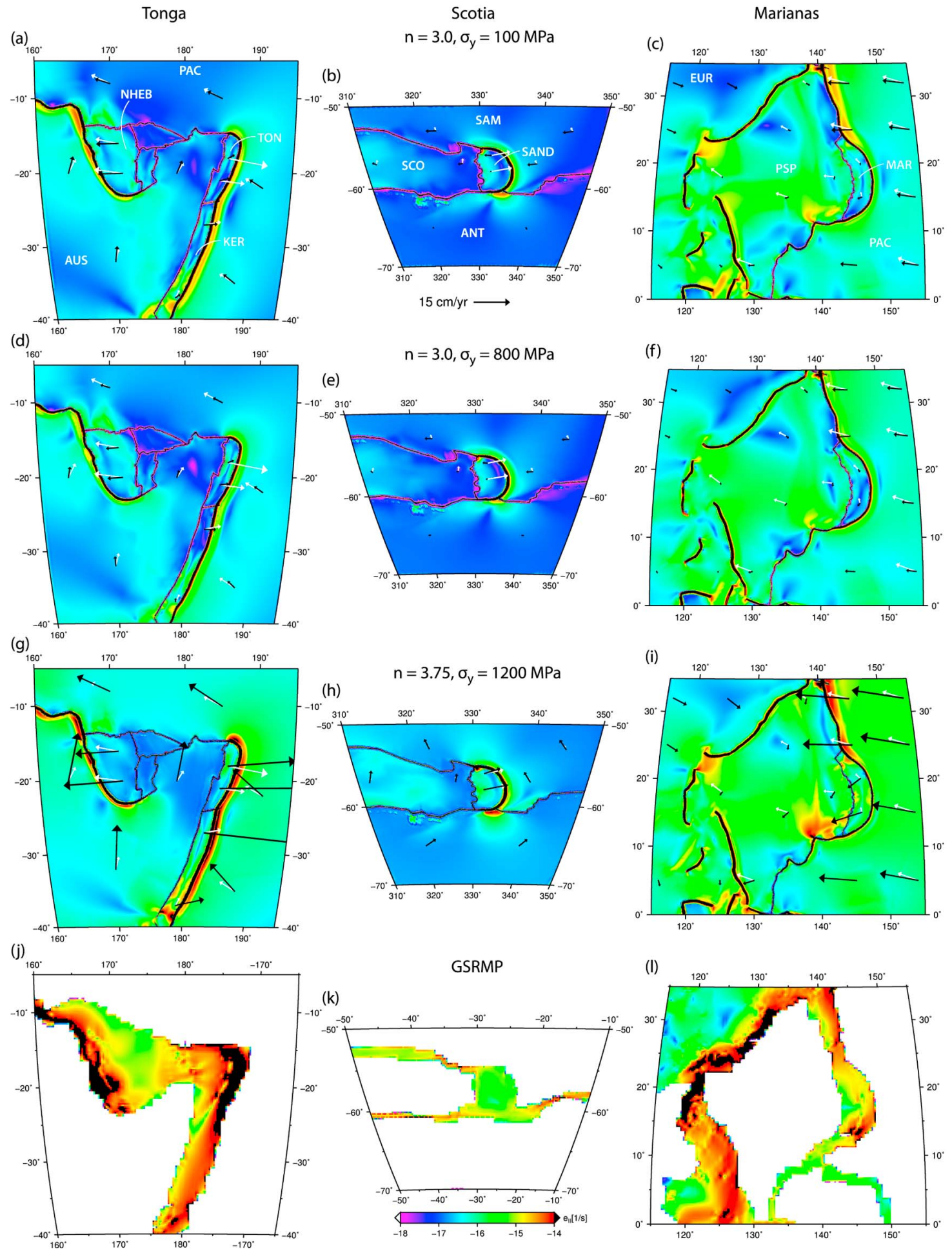

Figure 10. Comparison of surface strain rates. (left to right) Tonga, Scotia, Marianas. (top to bottom) Case 2, $\sigma_{y}=100 \mathrm{MPa}$ and $n=3.0$; Case 5, $\sigma_{y}=800 \mathrm{MPa}, n=3.0$; Case 12, $\sigma_{y}=1200 \mathrm{MPa}, n=3.75$; Global Strain Rate Map Project [Kreemer et al., 2003]. NNR_NUVEL1A plate motions are shown in white, Rhea velocities in black; plotted on top of the second invariant of the strain rate tensor.

geometry, and again fits the pattern in $\left(\sigma_{y}, n\right)$ space described by the schematic in Figure 5. The global shallow slab strain rate constraint provides a minimum stress exponent estimate of $\sim 3.0-3.5$ for yield stresses $<200 \mathrm{MPa}$, and slightly higher for higher $\sigma_{y}$. The average strain rate within the Tonga slab is somewhat less sensitive to rheology, and allows a wider range of parameter choices than the global shallow average, with a minimum acceptable value of around 3.0. This is 

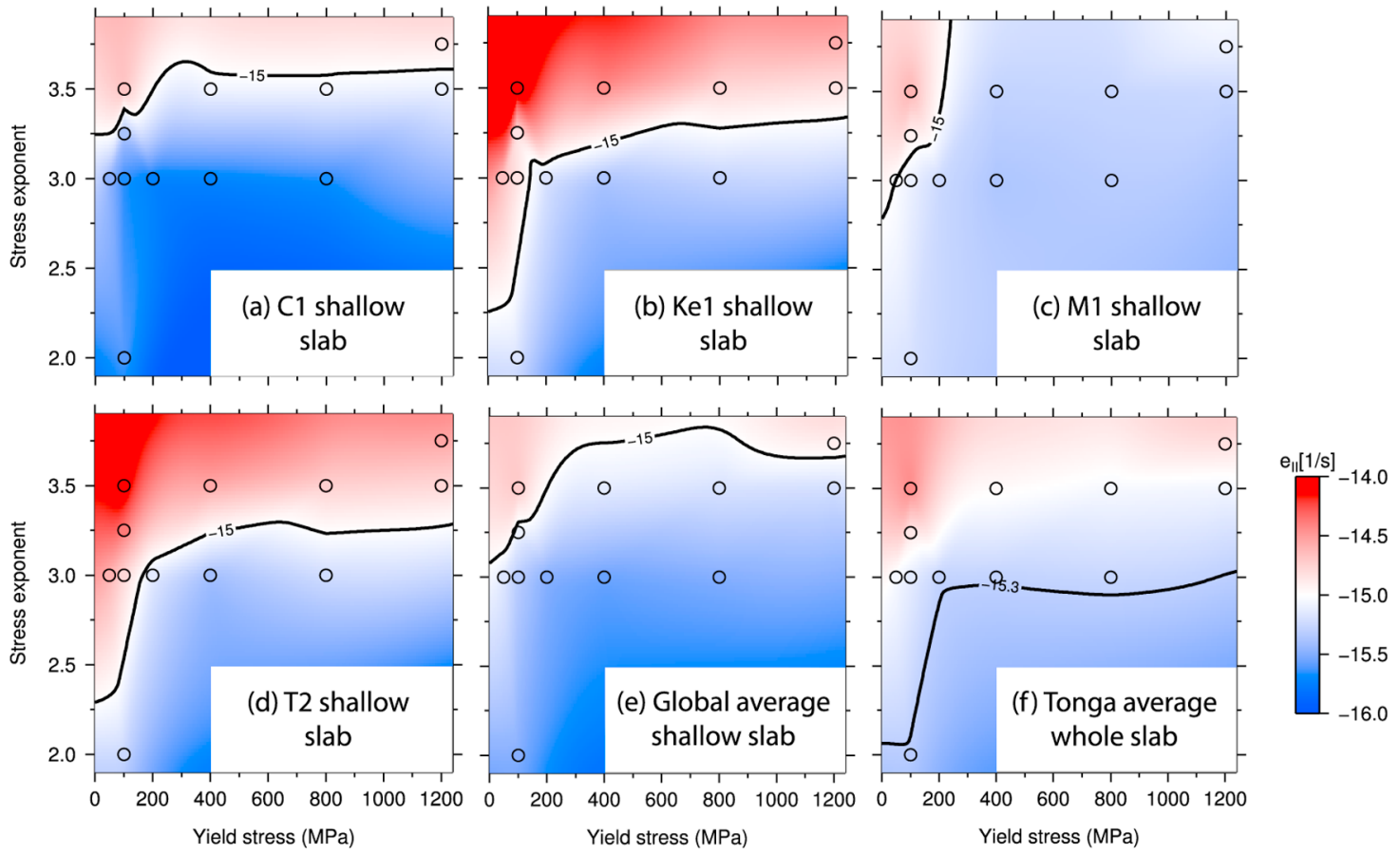

Figure 11. Global constraint for the strain rate in shallow slabs, and for the average Tonga slab. (a) Strain rates in the shallow part of the Chile cross-section, $\mathrm{C} 1$ in Figure 1; (b) Kermadec, Ke1; (c) Marianas, M1; (d) Tonga, T2; (e) Shallow slab average of the 14 cross-sections in Figure 1. Black contour: the global shallow slab strain rate constraint from seismicity of $10^{-15} \mathrm{~s}^{-1}$, which must minimally be achieved. (f) The average strain rate in the Tonga slab below $200 \mathrm{~km}$ depth, with the region-specific minimum constraint of $5 \times 10^{-16} \mathrm{~s}^{-1}$.

similar to the results found by Alisic et al. [2010], although in that study a much smaller parameter space was considered ( $n$ $=3.0$, and $\left.\sigma_{y}=\{50,100,200,400\}\right)$.

\subsection{State of Stress}

\subsubsection{Stress Drop}

[48] The stress drop estimates for large moment magnitude deep earthquakes form a lower limit of the stress that the slab must sustain. The 1994 Bolivia $M_{W} 8.3$ earthquake at $647 \mathrm{~km}$ depth experienced a minimum frictional stress of $55 \mathrm{MPa}$ and a static stress drop of $114 \mathrm{MPa}$ [Kanamori et al., 1998]. There are several other deep earthquakes with large predicted stress drop in the same region, including the 1970 Colombia $M_{W} 8.3$ event with a stress drop of $68 \mathrm{MPa}$ [Fukao and Kikuchi, 1987; Ruff, 1999]. Although these large stress drops are only measured in few cases, they imply that at least in the Bolivia-Colombia region stresses of around $100 \mathrm{MPa}$ are present. In Alisic et al. [2010] it was shown that global convection models can sustain such stresses at the depth of deep earthquakes.

\subsubsection{Surface Stress Regime}

[49] The state of stress in overriding plates in the models is compared to stress regime observations (Figure 12). The state of stress at the surface indicates that the overriding plates in the Aleutians (Figure 12c), Peru and Chile (Figure 12e), Japan and the Kuriles (Figure 12f) are in compression, which is in agreement with observations in the literature [Jarrard, 1986; Lallemand et al., 2005]. Similarly, the tensional regime in the overriding plate in the New Hebrides, Tonga and Kermadec region (Figure 12d) is predicted correctly. However, the Marianas and Scotia areas (Figures 12a and $12 b)$ show compression, which does not fit the observations. These are regions where the microplate motions in the numerical models do not correspond to inferred plate motions (see Figure 10 and section 3.5.1). In the Marianas region, this is related to the Philippine Sea plate directly to the west of the Marianas microplate. Instead of moving westward and subducting under Okinawa and the Philippines, the plate is stuck as the subduction zones on the west of the plate are not contiguous, with gaps located at Taiwan and at Luzon in the Philippines orogen. Surface strain rates in the gaps are high $\left(\sim 10^{-15}\right.$ to $\left.10^{-14} \mathrm{~s}^{-1}\right)$, and the Philippine Sea plate is in strong southeast-northwest compression (see Figures 10c, 10f, 10i, and 12b).

[50] The surface stress axis orientations do not vary significantly as a function of the stress exponent, yield stress, or lower mantle tomography strength. This indicates that in light of the tested parameters, regional characteristics such as interplate coupling and the geometry of subduction zones and plates are major contributing factors to the state of stress at the surface, rather than the rheology law. This was also determined by Stadler et al. [2010], who found that an increase in interplate coupling between the Nazca and South America plates in the Peru area strongly rotated the compression axes at the surface from trench-parallel to trenchperpendicular. 



(e)

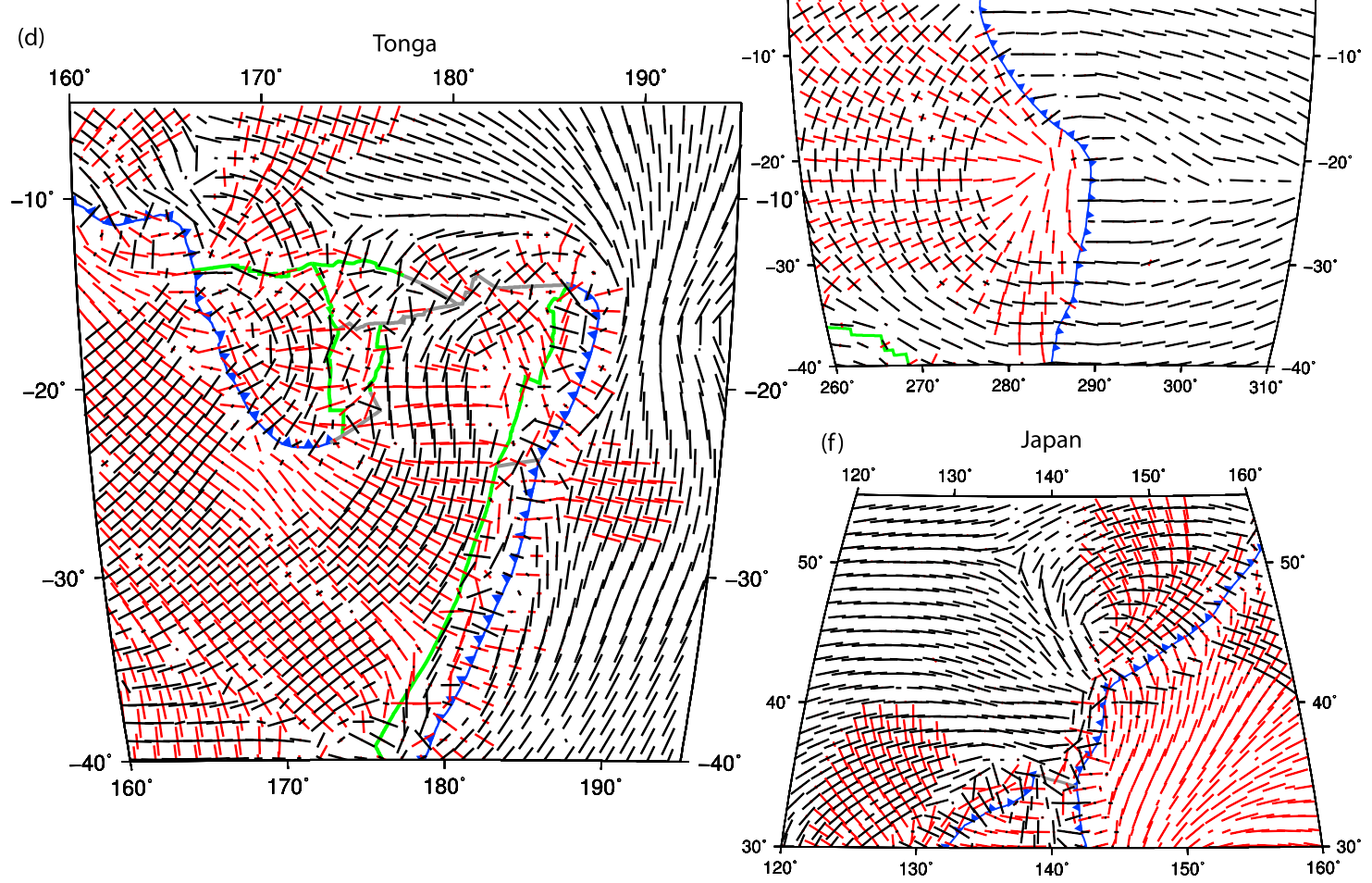

Figure 12. Regional state of stress at the surface for Case 2. Compression axes in black, tension axes in red. (a) Scotia; (b) Marianas; (c) Aleutians; (d) Tonga; (e) South America; (f) Japan.

\subsubsection{Stress Regime in Slabs}

[51] Previous studies have addressed the state of stress in slabs from earthquake focal mechanisms [Isacks and Molnar, 1971; Alpert et al., 2010]. It was shown earlier that changes in the radial viscosity profile can have a significant effect on the state of stress in slabs [Vassiliou and Hager, 1988;
Gurnis and Hager, 1988; Alpert et al., 2010]. Billen et al. [2003] also found that the stress orientation in slabs is sensitive to the relative viscosity of the slab, lower mantle, and wedge. We determine the model stress regime in slabs by comparing the orientation of the compressional and tensional axes of the stress tensor to the principal axes from earthquake 

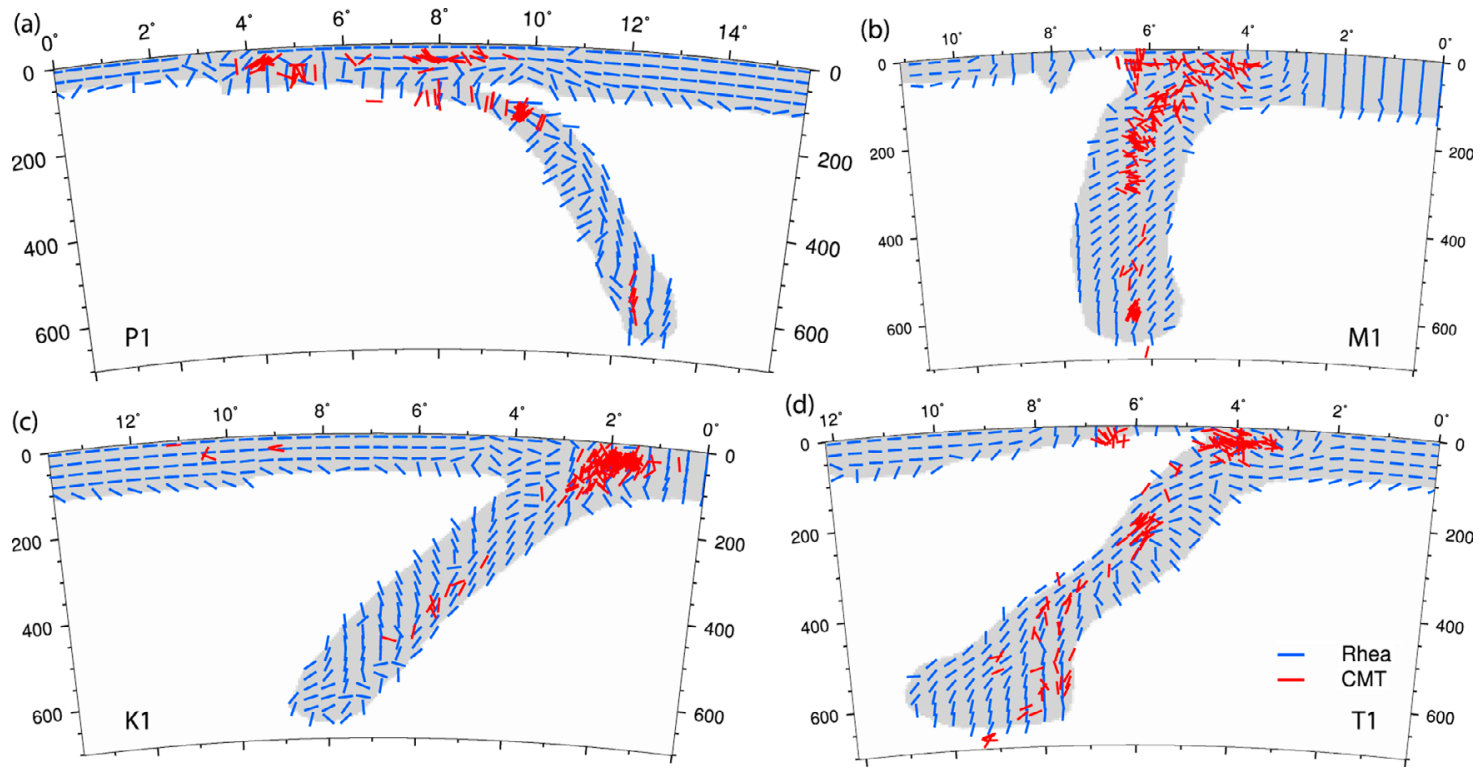

Figure 13. Cross-sections of state of stress in slabs; Case 2. Blue dashes: Rhea compression axes. Red dashes: CMT compression axes. The grey areas denotes nondimensional temperatures below 0.8. (a) Peru, P1 (see Figure 1 for location of cross-sections); (b) Marianas, M1; (c) Kurile, Ku1; (d) Tonga, T1.

focal mechanisms. We also investigate the effect of changes in yield stress and stress exponent on the stress regime.

[52] The compression axes from the CMT solutions are typically not precisely matched by the model compression axes. However, the general trends in stress regimes approximately fit the earthquake data, as shown for Case 2 in Figure $13\left(n=3.0, \sigma_{y}=100 \mathrm{MPa}\right)$. In Peru (Figure 13a), the observations show that the slab is in tension in the upper $300 \mathrm{~km}$, and in compression in the deep slab. This pattern is also seen in the model results. A similar stress regime is observed in both data and model for the Marianas (M1) cross-section (Figure 13b). The Kurile (Ku1) and Tonga (T1) cross-sections (Figures 13c and 13d) show compression throughout the slabs, which is also reproduced in the model. The misfit of model compression axes with respect to CMTs averaged for all cross-sections globally shows little sensitivity to the rheology. Therefore, we find that the state of stress in slabs does not constitute a useful test to determine their rheology in terms of yield stress and stress exponent.

\subsection{Regional Dynamics}

\subsubsection{Microplate Kinematics and Trench Rollback}

[53] The motions of microplates and trenches are essential for our understanding of the convective system, as trench rollback occurs in areas of plate bending that are critical for overall plate motions. This rollback is highly sensitive to rheology, and is therefore useful for testing our models. Microplates are defined as plates with small surface areas such as the New Hebrides, Tonga, Kermadec, Marianas and Sandwich plates studied here. Although the Easter Island microplate is resolved and included in our models, we have not used its motions as model constraints here. The New Hebrides, Tonga, and Kermadec microplates (Figure 10, left) and the Sandwich plate (Figure 10, middle) are rapidly rolling back (white arrows) [Bird, 2003], while the Marianas plate is observed to be stationary (Figure 10, right). The model with stress exponent 3.0 and yield stress $100 \mathrm{MPa}$ (Case 2) correctly predicts New Hebrides and Kermadec rollback both in magnitude and direction (Figure 10a). The rollback in Tonga is underpredicted, and Sandwich even exhibits trench advance in the dynamic model (Figure 10b); the modeled Marianas plate is close to stationary (Figure 10c). An increase in yield stress from 100 to $800 \mathrm{MPa}$ (Case 5) reduces the velocity of the plates, especially the Pacific and Australian plates, and the New Hebrides microplate (Figures 10d-10f). The Tonga, Kermadec, Marianas, and Sandwich microplates are not affected as much. Generally, the major plates appear to be more strongly affected by the increase in yield stress than microplates, especially the ones connected to subducting slabs (e.g., the Pacific, Australia, Cocos plates in Figures $3 \mathrm{a}$ and $3 \mathrm{~b}$ ). The ease with which these major plates subduct is governed by the amount of weakening in the slab hinges, and therefore by the yield stress. In the model with the highest yield stress and stress exponent (respectively $1200 \mathrm{MPa}$ and 3.75 , Case 12, Figures $10 \mathrm{~g}-10 \mathrm{i}$ ), all plates are moving significantly faster than in the other models. In this case, microplates appear to be more strongly influenced by the increased nonlinearity than the major plates, since the enhanced localization of deformation affects smallscale features. Rollback is strongly overpredicted in the NewHebrides, Tonga, Kermadec and the Marianas. The Sandwich microplate exhibits the correct amount of rollback, but the surrounding plates are moving too fast, as do the major plates in the other study areas.

[54] All trenches addressed here roll back in various frames of reference including hot spot reference frames, except for the Marianas, which shows rapid trench advance in hot spot reference frames [Funiciello et al., 2008]. Because changes in rheology affect net rotation (see section 3.2.4), we prefer to study the effect of rheology on trench motion in a no-netrotation frame of reference. The amount of trench rollback $v_{r}$ (defined as the magnitude of the microplate velocity 
perpendicular to the trench, positive for rollback) depends foremost on the stress exponent, and to a lesser extent on the yield stress for small yield stresses only (Figures 14a, 14d, $14 \mathrm{~g}$, and $14 \mathrm{j})$, exhibiting the same pattern in $\left(\sigma_{y}, n\right)$ space as illustrated in Figure 5. In order to match the observed rollback, generally a stress exponent of around 3.25 is required when yield stresses larger than $200 \mathrm{MPa}$ are used. The Sandwich microplate requires a higher stress exponent of 3.5-3.75 to fit the rollback constraint (Figure 14j).

[55] For each of the microplates, we plot the trench rollback velocity $v_{r}$ in relation to subducting plate velocity $v_{s}$ (also defined perpendicular to the trench) and the second invariant of the strain rate in shallow slabs $\left(\dot{\varepsilon}_{\mathrm{II}}\right)$, as the stress exponent and yield stress are varied (Figures $14 \mathrm{~b}-14 \mathrm{c}, 14 \mathrm{e}-14 \mathrm{f}, 14 \mathrm{~h}-$ $14 \mathrm{i}$, and $14 \mathrm{k}-14 \mathrm{l})$. The magnitudes of the quantities $v_{r}, v_{s}$, and $\dot{\varepsilon}_{\text {II }}$ increase when the stress exponent is increased. We can observe several important characteristics when the stress exponent is kept constant while yield stress increases. First, the rollback, subduction velocity and strain rate decrease with increasing yield stress. Second, the change in $v_{r}$ and $v_{s}$ decreases with increasing yield stress: the decrease in $v_{r}$ and $v_{s}$ is significant when the yield stress is changed from 50 to $100 \mathrm{MPa}$ and from 100 to $200 \mathrm{MPa}$, but for higher yield stresses the change in rollback and subducting plate velocity is small. This effect is stronger for higher stress exponents, and conforms to the two domains described by Figure 5. Third, models with the same stress exponent fall more or less on the same line in $\left(v_{s}, v_{r}\right)$ space. For the four microplates, these lines have an increasing slope and shift towards larger absolute values of rollback when the stress exponent is increased. This indicates that an increase in $n$ has more effect on the rollback than on the velocity of the subducting major plate. The ability of microplates to roll back depends on strain localization, and therefore microplates have a stronger response to higher stress exponents than large plates.

[56] Analysis of the set of constraints formed by the observed values of $v_{r}, v_{s}$, and the minimum constraint on $\dot{\varepsilon}_{\mathrm{II}}$ in shallow slabs, e.g., $10^{-15} \mathrm{~s}^{-1}$, shows that the three constraints are close to intersecting in $\left(v_{s}, v_{r}\right)$ space for the Marianas and New Hebrides, and a cluster of models approximately fits all constraints. For Tonga and Sandwich, several models are close to fitting both the $v_{r}$ and $v_{s}$ constraints, but the strain rate for those cases is systematically too low and therefore no model fits all three constraints simultaneously. Generally, the models that perform best with respect to microplate kinematics have stress exponents and yield stress combinations of respectively [3.0, 3.25] and $[50,100] \mathrm{MPa}$, or $[3.5,3.75]$ and $[400,1200] \mathrm{MPa}$.

[57] We have shown that trenches and microplates above the subducting hinge display a variety of behaviors, from rapidly rolling back to being stationary. This is intimately linked to the amount of yielding in the slab hinge, slab morphology, the presence of high viscosity structures in the lower mantle beneath the slab tip, and the magnitude and orientation of velocity in the slab with respect to the plate. In the Marianas, the velocity in the slab is of the same magnitude as that of the subducting plate, and is approximately aligned with the slab (Figure 15a). This suggests that the modeled slab is in a stable configuration, and both the trench and the Marianas microplate are stationary. The hinge of the Marianas slab contains only a limited amount of yielding, and the yielding does not extend oceanward of the surface intersection of the plate boundary. Additionally, there is a high-viscosity structure in the lower mantle centered below the slab tip (Figures 9d and 9g), which might anchor the slab in its current vertical position. The Tonga area displays a different behavior: the slab sinks vertically into the mantle with a velocity larger than the subduction velocity of the Pacific plate (Figure 15c). This sinking is not aligned with the slab, which is less steep than for example the Marianas slab. This results in rapid rollback of the trench and the Tonga microplate with ample yielding in the slab hinge. The Tonga slab reaches into the transition zone, and borders a large high viscosity structure in the lower mantle (Figure 9). The complex slab shape implies that this structure could (partially) anchor the slab and cause internal deformation of the slab rather than pure lateral motion of the entire slab. The New Hebrides slab exhibits even stronger motion not aligned with the slab (Figure 15b), as it is moving backward with a velocity significantly larger than the subducting plate velocity. There is substantial yielding in the hinge and within the microplate which is rolling back rapidly. The New Hebrides slab does not extend to the lower mantle and is not anchored. The entire slab can therefore move freely in a lateral sense, rather than deform to a more complex morphology. The velocities at the surface and within the mantle in the Sandwich area are overall small compared to those in the other crosssections (Figure 15d), leading to small strain rates at the surface and in the slab. Yielding in the slab hinge is minimal, and the Sandwich microplate is more or less stationary in this model with $n=3.0$. The slab is subducting more slowly than the other slabs we considered, since it is shorter and therefore has less negative buoyancy. The velocity in the slab is aligned and of the same magnitude as that of the subducting South America plate. As illustrated in Figure 10, the Sandwich microplate only displays rollback when a large stress exponent of 3.75 is used. This allows stronger localization of deformation, and therefore more weakening in the hinge zone and stronger decoupling of motion between South America and the Sandwich plate.

[58] We found that the magnitude of the velocity in plates and slabs as well as the rollback varies a great deal with the rheology. In contrast, the velocity orientation in slabs, much like the state of stress, does not vary significantly with yield stress or stress exponent; therefore the direction of slab motion and the stability of subduction zones appear to be more affected by regional factors (such as geometry of slab and plates, and presence of lower mantle structure) than by rheology.

\subsubsection{Lateral Flow Field Around Slabs}

[59] We now turn to the lateral flow around slabs at various depths in the Tonga, Japan, and Marianas regions. The lateral velocity at $400 \mathrm{~km}$ depth differs considerably in orientation from the surface velocity pattern (Figures 16a-16c and 16d16f), often showing return flow from plate motions. In general, lateral flow near slabs at $400 \mathrm{~km}$ depth is perpendicular to the strike of the trench (see Figures 16d-16f), indicating that the orientation of mantle flow is mostly governed by the downward motion of the subducting slabs. There is toroidal flow around the edges of the slabs, but its lateral extent is limited. In the Tonga-Fiji area (Figure 16, left) the interaction of flow around multiple slabs in close vicinity results in a complex flow pattern in the upper mantle. The toroidal flow around the Tonga slab causes some trench-lateral flow in the 



Figure 14. (top to bottom) Marianas, M1; New Hebrides, N1; Tonga, T1; Sandwich, S1. (left) Variation of amount of rollback $v_{r}$ with yield stress and stress exponent in several slabs. The contour denotes the observed rollback. (middle) Rollback velocity versus subducting plate velocity, color coded by stress exponent. The black dashed lines denote the observed rollback (horizontal) and subduction velocity (vertical), the solid contour line shows the minimum shallow slab strain rate constraint of $10^{-15} \mathrm{~s}^{-1}$. Above the line as indicated by the arrows, modeled strain rates are higher than the minimum constraint. The dotted lines show trends when the stress exponent is held constant between models $(n=3.0$ and 3.5). (right) Rollback velocity versus subducting plate velocity, but with data points color coded by yield stress. Note: Subducting and rollback velocities are both perpendicular to the trench. 
(a)

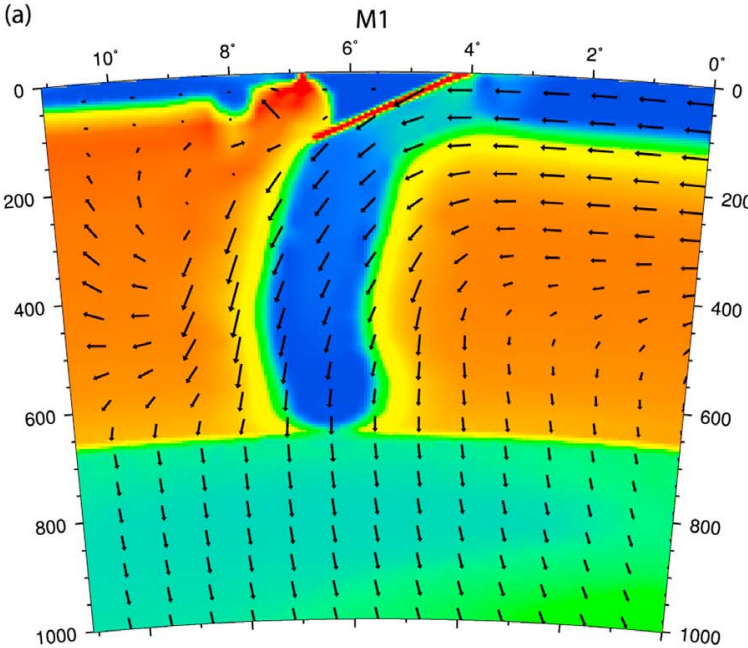

(b)

(c)
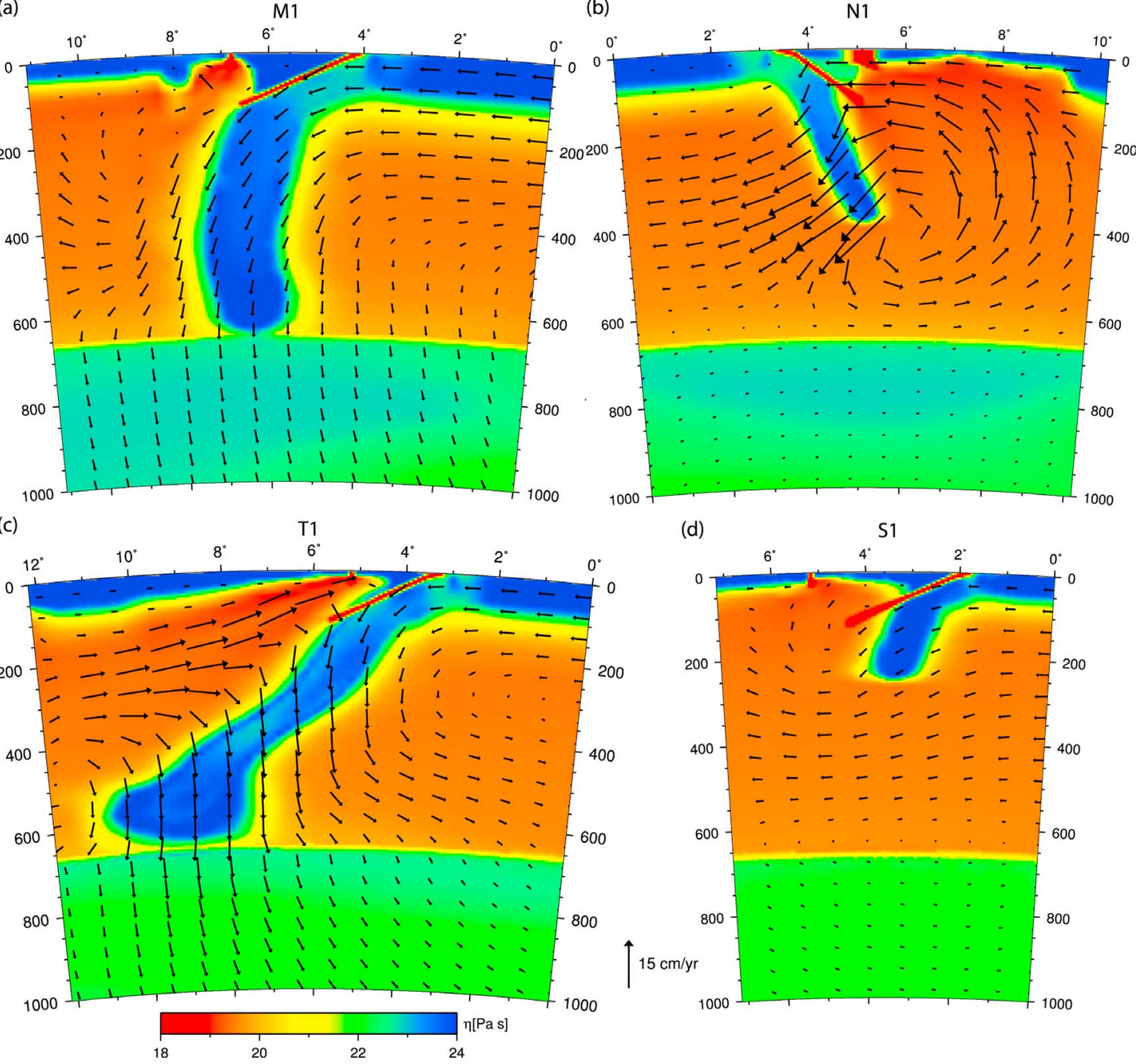

(d)

(d) S1

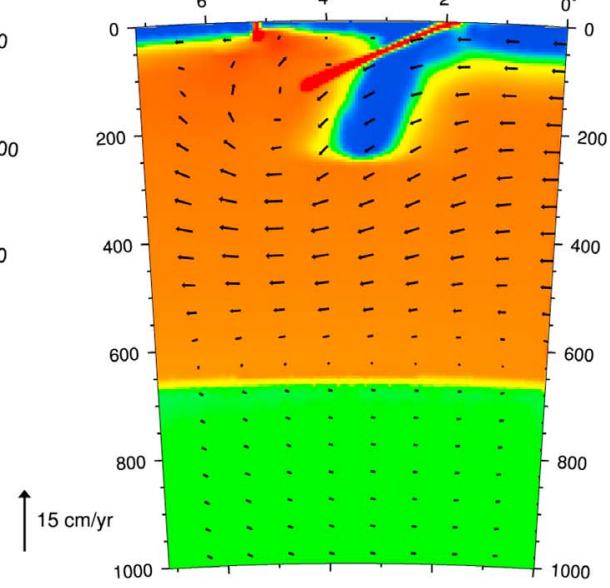

Figure 15. Cross-sections through slabs and microplates of Case 2, with stress exponent $n=3.0$ and yield stress $\sigma_{y}=100 \mathrm{MPa}$. Arrows: velocity; background color: viscosity. (a) Marianas, M1; (b) New Hebrides, N1; (c) Tonga, T1; (d) Sandwich, S1.

mantle wedge east of and above the New-Hebrides slab, and fast rollback of both slabs creates a strong paddle effect. There is also some lateral component to the flow in the mantle wedge above the Marianas slab, to the west of the trench (Figure 16, middle). Unlike Tonga, the Marianas slab is not interacting with the lateral flow around it because its tip is anchored in the lower mantle, and therefore there is no paddle effect and less trench-perpendicular flow. However, in general, we do not observe the pervasive presence of trench-parallel flow that e.g., Long and Silver [2008, 2009] require to explain the sub-slab or mantle wedge trenchparallel fast directions inferred from seismic anisotropy.

[60] Of note is the increase in lateral velocities at $400 \mathrm{~km}$ depth with respect to surface velocities, by up to a factor of three in the model shown $\left(n=3.0, \sigma_{y}=100 \mathrm{MPa}\right)$. This occurs most significantly in the mantle wedges on top of the subducting slabs, which is to the west of the Tonga slab and to the east of the New Hebrides slab (Figure 16d); to the southwest of the Marianas slab (Figure 16e); to the west of the Japan slab, and to the north of the Kurile slab (Figure 16f). The strain weakening in mantle wedges leads to low viscosities which again leads to high (lateral) velocities and strain rates, due to the strongly nonlinear nature of the rheology. This velocity increase factor correlates strongly with the stress exponent: in models with $n=3.5$, it can be as much as 5 to 10 , as was also observed by Jadamec and Billen [2010], and studied in detail by Billen and Jadamec [2012].

[61] The lateral flow at $800 \mathrm{~km}$ depth is much smaller due to the increase in viscosity with depth and the purely linear viscosity in the lower mantle (Figures 16g-16i). The flow beneath slab tips experiences little effect on its orientation from the presence of slabs or the lower mantle viscosity structure. Only in the model with stronger lower mantle structure (Case 14) does the lateral flow pattern extend deeper. In our models, the orientation of lateral flow does not depend on rheology, only the magnitude of flow in the upper mantle is affected by the stress exponent. 

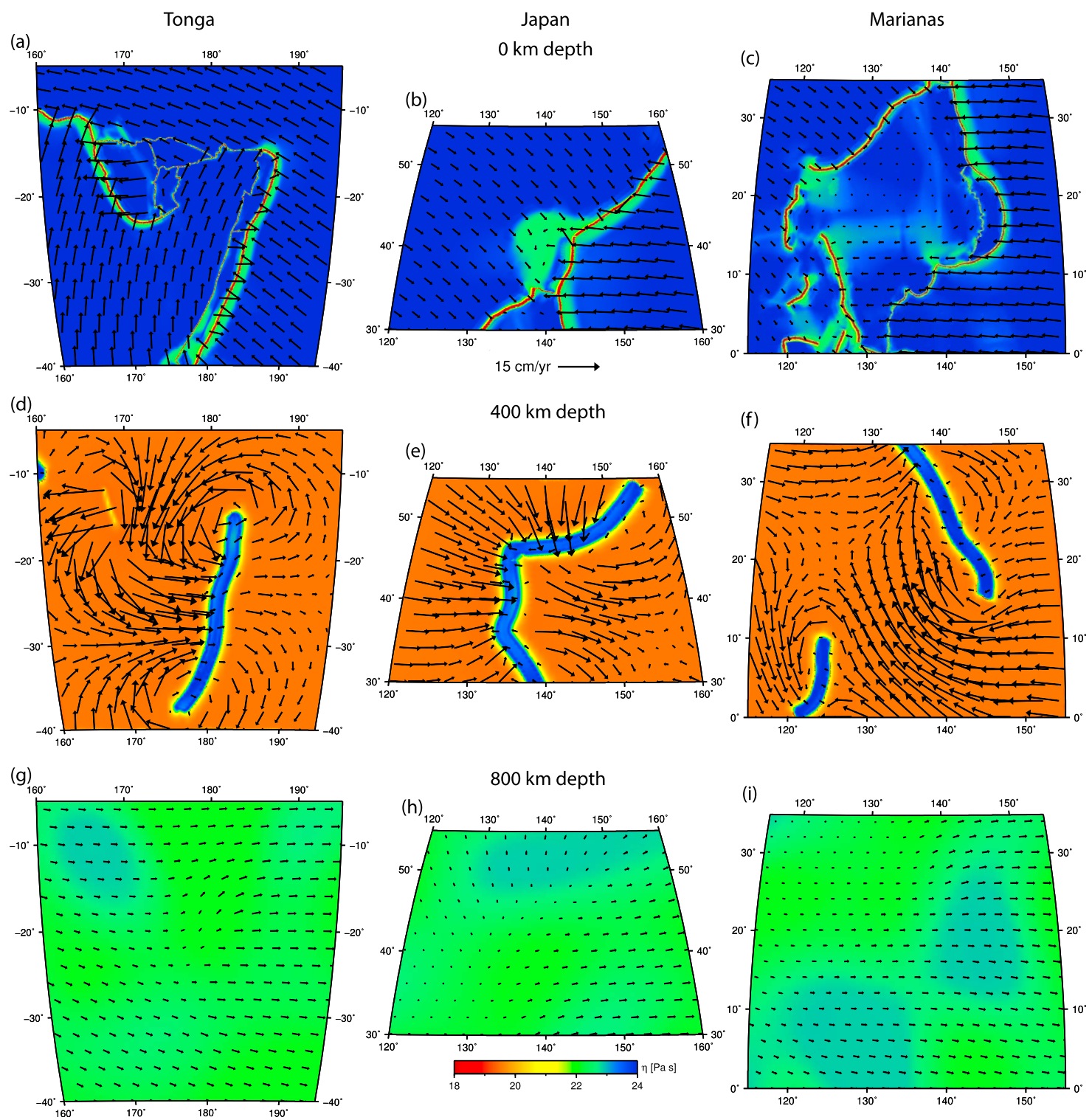

Figure 16. Lateral flow at depth, plotted on viscosity, for Case 2. (left to right) Tonga, Japan, Marianas. (top to bottom) Surface, $400 \mathrm{~km}, 800 \mathrm{~km}$ depth.

\subsection{Model Quality}

[62] We now assess our models using the entire suite of constraints: global plate motions, plateness, net rotation, strain rate, stress in slabs, and microplate kinematics. Each model is scored as having either a good, bad, or inconclusive fit to each constraint (Table 4). An important observation is that no model fits all constraints without ambiguity, and different constraints have different optimal parameter ranges for the stress exponent and yield stress. For instance, globally averaged plate speeds and net surface rotation are best fit for moderate stress exponents around 3.0, whereas a good fit to plateness and strain rate constraints ideally requires higher stress exponents of 3.5-3.75. The best fitting stress exponent for trench rollback depends on the individual trench, and ranges from $n=3.0$ to 3.75. As was demonstrated earlier, the plate motion angle misfit and the compression misfit in slabs do not allow distinction in quality among models.
Often several combinations of stress exponent and yield stress fit constraints equally well, leading to non-uniqueness, illustrated by contour lines of fit to model constraints in the $\left(\sigma_{y}, n\right)$ parameter space for plate motions, net rotation, minimum strain rate, and trench rollback. Another notable observation is the great variability in how easily constraints are met. Some constraints are fit for almost the entire parameter space tested, such as the minimum strain rate in the Tonga slab, whereas others are only met as an exception (for example the Sandwich rollback).

[63] To determine a 'best' model, one could count the constraints that are met, partially met, or not met, shown in the last column of Table 4 . There are some models with good scores, but all have at least several constraints that are met only partially or even not at all. We consider the first-order test of global plate motion fit to be the most important, and therefore choose Case $2\left(\sigma_{y}=100 \mathrm{MPa}\right.$ and $\left.n=3.0\right)$ 
as our best model. Models with lower yield stress do not conform to the minimum stress drop constraint $(n=3.0$ with $\sigma_{y}<100 \mathrm{MPa}$, Case 1), and models with higher yield stress do not fit the minimum strain rate constraints $(n=3.0$ with $\sigma_{y} \geq 400 \mathrm{MPa}$, Cases 3, 4, and 5). Models with lower stress exponents have velocities that are too slow $(n<3.0$ for all $\sigma_{y}$, Case 6). Models with higher stress exponents typically have plate motions and net rotations that are too fast ( $n \geq 3.25$ with $\sigma_{y} \leq 200 \mathrm{MPa}$, Cases 7 and 8 ); increasing the yield stress along with the stress exponent partly mitigates this problem (Cases 9, 10, 11, and 12).

\section{Discussion}

[64] In this paper, numerical models of mantle convection with plates have been computed to study the rheology and dynamics of convection on both global and regional scales. The models have implications for the coupling between lower mantle structure and plate motions, the strength of slabs, and the effect of rheology on different plates. We will also discuss how the choices of model parameterization may affect the resulting slab deformation patterns, and briefly address the reliability of model constraints.

[65] We studied the effect of lateral variations in lower mantle viscosity on surface plate motions. Our results show that changes in density contrasts in the lower mantle affect the flow throughout the mantle including surface velocities. This suggests that there is a strong coupling throughout the domain between plates, slabs, and both the upper and lower mantle. Becker and O'Connell [2001] concluded that the addition of lower mantle density anomalies improves fit to observed plate motions by speeding up plates, and that the contribution of lower mantle density anomalies to the average plate torque is significant ( $\sim 30 \%$ of the total). Conrad and Lithgow-Bertelloni [2002] found that slabs in the lower mantle could not contribute to pull forces on plates due to the large viscosity contrast across the transition zone. Our models show a more complicated interaction of buoyancy forces and viscous drag in the mantle affecting plate motions. Generally, the increase in scaling factor $\omega$ from lower mantle seismic velocity anomalies to temperature anomalies results in structures with larger negative buoyancy, increasing overall flow as predicted by Becker and O'Connell [2001]. Plates with no subducting slabs or only short slabs therefore speed up. However, plates that have deep slabs connecting to highviscosity lower mantle structures slow down. To better understand this behavior, consider a Stokes sphere sinking in an incompressible viscous fluid. Its velocity $U$ is determined by the balance between buoyancy forces acting on the volume of the sphere as a function of the density difference between the sphere and the surrounding mantle $\Delta \rho$, and drag on the surface of the sphere as function of the mantle viscosity $\eta$ : $U=2 \Delta \rho g a^{2} / 9 \eta$ [see, e.g., Batchelor, 1967], where $a$ is the radius of the sphere, and $g$ the gravitational acceleration. In the work by Becker and O'Connell [2001] and by Conrad and Lithgow-Bertelloni [2002, 2004], a radially varying viscosity was assumed, and there exists only a density contrast between slabs and the surrounding mantle. The viscosity used in our models is temperature dependent and varies laterally within the lower mantle, which not only affects the buoyancy force acting on the volume of a sinking body, but also the viscous drag on its surface. An increase in density difference due to a larger scaling factor $\omega$ results in a faster sinking velocity of slabs. But when density differences are increased, the viscosity around the slab tip also increases due to the presence of lower mantle anomalies, slowing the slabs, more so than in models with a purely radially varying viscosity. Furthermore, the large-wavelength high-viscosity structures in the mantle do not sink faster like a slab in the upper mantle would. The large irregularly shaped features experience increased viscous drag, and the increase in negative buoyancy could be partially or even fully compensated.

[66] The plates and slabs in the models presented here are mechanically strong, with a viscosity around $10^{24} \mathrm{~Pa} \mathrm{~s}$, as a result of the temperature dependence of the viscosity. Only areas with localized deformation such as plate hinges have lower viscosities of $\sim 10^{22} \mathrm{~Pa}$ s due to strain rate weakening and plastic yielding. Earlier work by e.g., Billen and Hirth [2007] shows that generic kinematic time-dependent models of slab subduction require slabs with similar viscosities as those in our models, but with yield stresses of around $1000 \mathrm{MPa}$ and a stress exponent $n$ of 3.5. We have shown that models with such strong slabs perform well in producing plates with high plateness, but a stress exponent of 3.5 generally causes surface velocities and net surface rotations that are too high compared to observed values (compare Cases 10 and 11 , with $n=3.5$ and $\sigma_{y}=800$ and $1200 \mathrm{MPa}$, respectively). The yield stress of $1000 \mathrm{MPa}$ would well exceed the convective stress and therefore fall in Domain II of the schematic of Figure 5, not permitting a narrow constraint on its value. In contrast, Liu and Stegman [2011] inferred that slabs have to be weak with viscosities of $\sim 10^{21}$ to $5 \times 10^{21} \mathrm{~Pa} \mathrm{~s}$ in order to fit observed segmentation and curvature of the Farallon slab in time-dependent models with prescribed surface velocities, using a Newtonian rheology. If such low slab viscosities were used in our models, slabs would not act as stress guides or sustain large stress drops, and plates would display small plateness with little internal rigidity. It is not clear if our present models are inconsistent with the work of Liu and Stegman [2011] or not, as the recent history of Farallon slab subduction beneath North America has been one in which the slab is descending into a region previously dominated by flat-slab subduction, which presumably dramatically altered the mantle compared to most regions. Furthermore, our preferred values for $n$ and $\sigma_{y}(3.0$ and $100 \mathrm{MPa}$, respectively) result in slab break-off in timedependent models [Billen and Hirth, 2007; Andrews and Billen, 2009], as these studies require a significantly higher yield stress of 500-1000 $\mathrm{MPa}$ in order to preserve slab strength with time.

[67] The ongoing debate whether slabs are weak or strong exists partly because various studies address different aspects of slab strength. Linear models effectively take into account the integrated strength of slabs, where the viscosity in the hinge of the subducting slab equals that of the rest of the slab. Nonlinear models assess localized weakening, such that a lower viscosity is permitted in the hinge compared to the rest of the slab. An equivalent amount of slab deformation in Newtonian models would require overall weaker slabs compared to our models or those by Billen and Hirth [2007] due to the lack of localization of deformation. As was described in section 1, observations of bending-related faulting and 
Table 4. Table With Model Scores ${ }^{\mathrm{a}}$

\begin{tabular}{|c|c|c|c|c|c|c|c|c|c|c|c|c|c|c|c|c|c|c|c|}
\hline Model & Case & $\sigma_{y}$ & $n$ & $\omega$ & $\left|v_{p}\right|$ & $\alpha$ & $P_{1}$ & $P_{2}$ & NR & $\dot{\varepsilon}_{\mathrm{II}}$ & $\dot{\varepsilon}_{\mathrm{II}} \mathrm{T}$ & $\sigma_{d}$ & $C$ & $v_{r} \mathrm{M} 1$ & $v_{r} \mathrm{~N} 1$ & $v_{r} \mathrm{~T} 1$ & $v_{r} \mathrm{~S} 1$ & $v_{r}$ All & Total \\
\hline run97 & 1 & 50 & 3.0 & 0.1 & + & $\circ$ & $\circ$ & $\circ$ & + & 0 & + & - & $\circ$ & + & $\circ$ & 0 & - & ० & $3+, 6 \circ, 1-$ \\
\hline run104 & 2 & 100 & 3.0 & 0.1 & + & ० & $\circ$ & $\circ$ & + & 0 & + & + & $\circ$ & + & + & $\circ$ & - & O & $4+, 6 \circ, 0-$ \\
\hline run98 & 3 & 200 & 3.0 & 0.1 & + & O & 0 & $\circ$ & + & - & + & + & $\circ$ & o & + & ० & - & ० & $4+, 5 \circ, 1-$ \\
\hline run99 & 4 & 400 & 3.0 & 0.1 & ० & $\circ$ & - & - & + & - & + & + & $\circ$ & ० & - & - & - & - & $3+, 3 \circ, 4-$ \\
\hline run107 & 5 & 800 & 3.0 & 0.1 & ○ & $\circ$ & - & - & + & - & + & + & $\circ$ & ० & - & - & - & - & $3+, 3 \circ, 4-$ \\
\hline run 100 & 6 & 100 & 2.0 & 0.1 & - & $\circ$ & - & - & + & - & ० & + & $\circ$ & - & - & - & - & - & $2+, 3 \circ, 5-$ \\
\hline run102 & 7 & 100 & 3.25 & 0.1 & - & $\circ$ & + & + & - & + & + & + & $\circ$ & ० & ० & + & + & + & $6+, 2 \circ, 2-$ \\
\hline run101 & 8 & 100 & 3.5 & 0.1 & - & $\circ$ & + & + & - & + & + & + & $\circ$ & - & - & - & $\circ$ & - & $5+, 2 \circ, 3-$ \\
\hline run 105 & 9 & 400 & 3.5 & 0.1 & ० & ० & + & + & - & $\circ$ & + & + & $\circ$ & ० & - & - & $\circ$ & $\circ$ & $4+, 5 \circ, 1-$ \\
\hline run106 & 10 & 800 & 3.5 & 0.1 & 0 & ० & + & + & - & 0 & + & + & $\circ$ & 0 & 0 & 0 & O & O & $4+, 5 \circ, 1-$ \\
\hline run108 & 11 & 1200 & 3.5 & 0.1 & o & ० & $\circ$ & $\circ$ & - & 0 & + & + & $\circ$ & ० & + & ० & $\circ$ & ० & $2+, 7 \circ, 1-$ \\
\hline run109 & 12 & 1200 & 3.75 & 0.1 & - & O & + & + & - & + & + & + & $\circ$ & - & - & - & + & ० & $5+, 3 \circ, 2-$ \\
\hline run110 & 13 & 100 & 3.0 & 0.0 & + & o & $\circ$ & $\circ$ & + & $\circ$ & + & + & $\circ$ & + & + & ० & - & ○ & $4+, 6 \circ, 0-$ \\
\hline run94 & 14 & 100 & 3.0 & 0.25 & + & O & 0 & $\circ$ & + & 0 & + & + & $\circ$ & + & + & O & - & ० & $4+, 6 \circ, 0-$ \\
\hline
\end{tabular}

'The models are scored as ' + ' when a constraint is met, as ' $O$ ' when the score is ambiguous, and as ' - ' when the constraint is not met. Columns: $\sigma_{y}$ : yield stress in $\mathrm{MPa} ; n$ : stress exponent; $\omega$ : lower mantle tomography scaling between S-wave speeds and temperature; $\left|v_{p}\right|:$ plate speeds; $\alpha$ : plate velocity angles; $P_{1}$ and $P_{2}$ : plateness; NR: net rotation of the surface; $\dot{\varepsilon}_{\mathrm{II}}$ : second invariant of the strain rate in shallow slabs; $\dot{\varepsilon}_{\mathrm{II}}$ T: second invariant of the strain rate in the Tonga slab; $\sigma_{d}$ : stress drop; $C$ : compression misfit in the slab; $v_{r}$ : trench rollback in the Marianas (M1), NewHebrides (N1), Tonga (T1), and Sandwich (S1). The trench rollback for these four cross-sections is combined in $v_{r}$ All for the total model score.

serpentinization in outer rises [Ranero et al., 2003; Grevemeyer et al., 2005] as well as gravity measurements showing reduction in flexural rigidity towards the trench [Billen and Gurnis, 2005; Arredondo and Billen, 2012] support the notion of localized weakening in hinges of subducting plates present in our models.

[68] The dynamic models reproduce the observed variation in trench rollback, ranging from rapid rollback (Tonga, New Hebrides) to stationary trenches (Marianas). This amount of rollback is predominantly affected by the dip and length of the slab, i.e. by subduction duration [Gurnis et al., 2004]. The Sandwich slab is observed to roll back rapidly, whereas our models have great difficulty predicting this rollback for such a short slab that reaches to only about $250 \mathrm{~km}$ depth. Considering the subduction initiated at about 45 Ma [Barker, 2001; Gurnis et al., 2004] and the observed rapid trench rollback, a far larger length of slab would be expected. Recent P-wave tomography models suggest the presence of a dipping high seismic velocity anomaly beneath the Sandwich trench down to the transition zone and beyond, which could be interpreted as the continuation of the Sandwich slab [Li et al., 2008; van der Meer et al., 2009]. This additional negative buoyancy would significantly increase the ability of the Sandwich trench to roll back, and potentially alter the state of stress at the surface to better match observations of tension (section 3.4.2 and Figure 12).

[69] The effect of rheology on plate motions varies between plates depending on the geometry and distribution of slabs. Generally, the major plates appear to be more strongly affected by the increase in yield stress than microplates, especially ones connected to subducting slabs (e.g., the Pacific, Australia, and Cocos plates in Figures 3a and 3b). The ease with which these major plates subduct is governed by the amount of weakening in the slab hinges, and therefore by the yield stress. In contrast, the increase in stress exponent has a stronger effect on the microplates than on the major plates, as small-scale features are more significantly influenced by localization of deformation. Stronger nonlinearity enhances decoupling of microplates from the surrounding large plates, and therefore allows faster trench rollback in the Tonga, New Hebrides, Marianas, and Sandwich areas.
[70] Choices made in model plate boundary parameterization have implications for the modeled slab deformation and plate-mantle coupling. There is a trade-off between the ability of a slab to accommodate the deformation required for subduction, and the ability to effectively transmit slab pull [Wu et al., 2008]. Here, a larger stress exponent results in faster plate motions, and suggests that stronger localization of deformation enhances plate motion and is more important than the reduced slab pull from weaker slabs. Furthermore, in some cases, the modeled deformation indicated by low-viscosity zones might involve some thinning instead of bending as the plate approaches the hinge. Although the dip angles from large thrust earthquakes were used for our parameterization, it is possible that the dipping fault is too steep near the surface, which could potentially be avoided with subduction zones that have a more curved top interface. Finally, the dynamic models have a free slip and not a free surface, which may limit the ability to have onesided subduction [Crameri et al., 2012].

[71] Only positive velocity anomalies have been incorporated from tomography in the lower mantle, and also the upper mantle does not contain active upwellings. The addition of the driving force resulting from positive temperature anomalies could increase plate motions, in particular in the upper mantle beneath ridges [van Summeren et al., 2012], possibly allowing a lower stress exponent. However, especially in the upper mantle where the viscosity is nonlinear, it might be expected that low-viscosity upwellings have less impact on overall flow, as the nonlinearity narrows their lateral extent compared to models where only a temperature dependence of viscosity is assumed. The addition of a predefined low-viscosity asthenosphere beneath the plates would lessen the need for high stress exponents $(n \geq 3.5)$ to decouple plates from the viscous mantle. There are several possible causes for such a low-viscosity layer: proximity of the adiabat to the solidus, presence of melt, and a temperature overshoot from convection [Richards et al., 2001]. This inherent low-viscosity asthenosphere decouples the plates from the more sluggish mantle and allows them to speed up [Richards et al., 2001; Crowley and O'Connell, 2012; van Summeren et al., 2012]. 
[72] Aside from the component of ridge push force due to active upwellings in the upper mantle, our models also do not include the buoyancy force of the $670 \mathrm{~km}$ phase transition topography caused by lateral changes in temperature, or the plate driving forces resulting from gravitational potential energy [Ghosh and Holt, 2012].

[73] In this study, we extensively rely on plate motion models, minimum strain rate estimates, and state of stress to test our dynamic models. In recent years, the plate motion models as well as estimates of net surface rotation have improved with the increased availability of GPS data and an improved understanding of plate motions since $150 \mathrm{Ma}$ [Torsvik et al., 2010; Argus et al., 2011]. We found that the differences between the NNR NUVEL1A, NNR GSRM-2, and NNR_MORVEL56 models are significantly smaller than variations between dynamic models related to choices in rheology [DeMets et al., 1994; Kreemer et al., 2006; Argus et al., 2011]. Therefore, in light of the model analysis described here, the use of NNR_NUVEL1A has proven to be adequate, and errors associated with rotation poles in the plate motion models are insignificant for the purposes of our analysis. Minimum strain rate estimates from seismic moment release [Bevis, 1988; Holt, 1995; Nothard et al., 1996] are an important component of the constraints on mantle convection models in this study. However, these estimates are based on accumulated seismicity within the past century. We cannot tell if there exists a temporal variation in seismicity with a period longer than our measurement period, and therefore we do not know with certainty how representative these minimum strain rate estimates are for slabs that have been subducting for tens of millions of years [Gurnis et al., 2000b]. We have not made an attempt to compare misfits in the predicted state of stress between different studies. The state of stress and its misfit with stress determined from CMT focal mechanisms vary significantly from slab to slab and also within slabs, and thus we conclude that globally averaged misfits do not convey much information. Additionally, no comparison with previous work addressing the state of stress in slabs has been made, since these studies all have the viscosity structures prescribed [Vassiliou and Hager, 1988; Billen et al., 2003; Alpert et al., 2010], resulting in an absence of feedback between the state of stress and viscosity. It is unclear whether this may have implications for the resulting stress field in those models.

[74] It is to be expected that the coupling and rheology of plates vary depending on for example local tectonic setting, pre-existing faulting in the subducting plate [Ranero et al., 2003], and the amount of water being released from the slab during subduction [Hebert et al., 2009]. The effect of spatial variation in plate boundary strength has not yet been extensively explored, but could be used to gain a better understanding of interplate coupling and its effect on plate motions and state of stress in plates. Furthermore, the models presented in this study are instantaneous solutions to the Stokes equation. The computational cost of these global models (circa 144,000 computing hours per model) prevented the incorporation of time dependence. The small grid size limits the permissible time step size, and therefore significantly increases computational cost compared to a coarse mesh with a large time step. Time-dependent models would allow us to study the evolution of plates and slabs through time, providing an additional constraint on rheology, as plates and slabs must be able to sustain their strength through significant intervals in geologic time. Additionally, time dependence allows tracking of strain accumulation, such that the development of anisotropic fabric as well as the effect of grain size reduction and recrystallization processes on viscosity could be addressed.

\section{Conclusions}

[75] We computed fully dynamic instantaneous global models of mantle convection with plates, incorporating a composite rheology with yielding. A local high resolution of $\sim 1 \mathrm{~km}$ allows us to study regional features such as trench rollback and microplate motions. The rheological parameters $\sigma_{y}$ (yield stress) and $n$ (stress exponent) govern the strength of materials, the nonlinearity of their behavior, and flow velocity magnitudes in the system. Global plate motions, trench rollback, net rotation, plateness, and minimum strain rates from seismic moment release provide important constraints on these rheological parameters. Although we are able to match general trends in the state of stress in plates and slabs, it does not allow for distinction in quality among models. We find that a model with $n=3.0$ and $\sigma_{y}=100 \mathrm{MPa}$ best fits the suite of model constraints. Plates and slabs are strong with a viscosity of $10^{24} \mathrm{~Pa} \mathrm{~s}$, with only localized weakening in slab hinges to $\sim 10^{22} \mathrm{~Pa} \mathrm{~s}$ accommodating deformation. This results in significant coupling throughout the model domain, from lower mantle structures to surface motions. The lateral flow around slabs is generally trench-perpendicular, induced by the strongly coupled downward motion of the subducting slabs, and therefore our models do not explain the significant trench-parallel flow inferred from shear-wave splitting analysis. The implementation of spatially varying model parameters such as plate boundary strength could be essential in achieving a new level of accuracy in numerical mantle convection models with plates.

[76] Acknowledgments. This work was partially supported by the NSF PetaApps program (OCI-0749334, OCI-0748898), NSF Earth Sciences (EAR-0426271, EAR-0810303), NSF CDI II (CMMI-1028889, CMMI-1028978), and the Caltech Tectonics Observatory (by the Gordon and Betty Moore Foundation). Computing resources on TACC Ranger, Lonestar, and Spur systems were provided through the NSF TeraGrid under grant TG-MCA04N026. The figures in this paper were produced using Generic Mapping Tools (GMT) and Paraview. Two anonymous reviewers are thanked for their detailed and constructive comments. This is contribution number 202 of the Caltech Tectonics Observatory.

\section{References}

Alisic, L., M. Gurnis, G. Stadler, C. Burstedde, L. C. Wilcox, and O. Ghattas (2010), Slab stress and strain rate as constraints on global mantle flow, Geophys. Res. Lett., 37, L22308, doi:10.1029/2010GL045312.

Alpert, L. A., T. W. Becker, and I. W. Bailey (2010), Global slab deformation and centroid moment tensor constraints on viscosity, Geochem. Geophys. Geosyst., 11, Q12006, doi:10.1029/2010GC003301.

Andrews, E. R., and M. I. Billen (2009), Rheologic controls on the dynamics of slab detachment, Tectonophysics, 464, 60-69, doi:10.1016/j.tecto. 2007.09.004.

Argus, D. F., R. G. Gordon, and C. DeMets (2011), Geologically current motion of 56 plates relative to the no-net-rotation reference frame, Geochem. Geophys. Geosyst., 12, Q11001, doi:10.1029/2011GC003751.

Arredondo, K. M., and M. I. Billen (2012), Rapid weakening of subducting plates from trench-parallel estimates of flexural rigidity, Phys. Earth Planet. Inter., 196-197, 1-13.

Barker, P. F. (2001), Scotia Sea regional tectonic evolution: Implications for mantle flow and palaeocirculation, Earth Sci. Rev., 55, 1-39.

Batchelor, G. K. (1967), An Introduction to Fluid Dynamics, Cambridge Univ. Press, Cambridge, U. K. 
Becker, T. W. (2006), On the effect of temperature and strain-rate dependent viscosity on global mantle flow, net rotation, and plate-driving forces, Geophys. J. Int., 167, 943-957, doi:10.1111/j.1365-246X.2006.03172.x.

Becker, T. W., and R. J. O'Connell (2001), Predicting plate velocities with mantle circulation models, Geochem. Geophys. Geosyst., 2(12), 1060, doi:10.1029/2001GC000171.

Bevis, M. (1988), Seismic slip and down-dip strain rates in Wadati-Benioff zones, Science, 240(4857), 1317-1319.

Billen, M. I., and M. Gurnis (2005), Constraints on subducting plate strength within the Kermadec trench, J. Geophys. Res., 110, B05407, doi:10.1029/2004JB003308

Billen, M. I., and G. Hirth (2007), Rheologic controls on slab dynamics, Geochem. Geophys. Geosyst., 8, Q08012, doi:10.1029/2007GC001597.

Billen, M. I., and M. Jadamec (2012), Origin of localized fast mantle flow velocity in numerical models of subduction, Geochem. Geophys. Geosyst., 13, Q01016, doi:10.1029/2011GC003856.

Billen, M. I., M. Gurnis, and M. Simons (2003), Multiscale dynamics of the Tonga-Kermadec subduction zone, Geophys. J. Int., 153(2), 359-388.

Bird, P. (2003), An updated digital model of plate boundaries, Geochem. Geophys. Geosyst., 4(3), 1027, doi:10.1029/2001GC000252.

Buffett, B. A., and D. B. Rowley (2006), Plate bending at subduction zones: Consequences for the direction of plate motions, Earth Planet. Sci. Lett., 245(1-2), 359-364, doi:10.1016/j.epsl.2006.03.011.

Burstedde, C., O. Ghattas, M. Gurnis, E. Tan, T. Tu, G. Stadler, L. C. Wilcox, and S. Zhong (2008), Scalable adaptive mantle convection simulation on petascale supercomputers, in SC '08: Proceedings of the International Conference for High Performance Computing, Networking, Storage, and Analysis, pp. 1-15, Curran Assoc., Red Hook, N. Y.

Burstedde, C., O. Ghattas, G. Stadler, T. Tu, and L. C. Wilcox (2009), Parallel scalable adjoint-based adaptive solution for variable-viscosity Stokes flows, Comput. Methods Appl. Mech. Eng., 198, 1691-1700, doi:10.1016/ j.cma.2008.12.015.

Burstedde, C., O. Ghattas, M. Gurnis, T. Isaac, A. Klöckner, G. Stadler, T. Warburton, and L. C. Wilcox (2010), Extreme-scale AMR, in SC '10, Proceedings of the International Conference for High Performance Computing, Networking, Storage, and Analysis, pp. 1-12, Curran Assoc., Red Hook, N. Y.

Burstedde, C., L. C. Wilcox, and O. Ghattas (2011), p4est: Scalable algorithms for parallel adaptive mesh refinement on forests of octrees, SIAM J. Sci. Comput., 33(3), 1103-1133, doi:10.1137/100791634.

Carminati, E., and P. Petricca (2010), State of stress in slabs as a function of large-scale plate kinematics, Geochem. Geophys. Geosyst., 11, Q04006, doi:10.1029/2009GC003003.

Christensen, U. (1984), Convection with pressure- and temperature-dependent non-Newtonian rheology, Geophys. J. R. Astron. Soc., 77, 343-384.

Conrad, C. P., and M. D. Behn (2010), Constraints on lithosphere net rotation and asthenospheric viscosity from global mantle flow models and seismic anisotropy, Geochem. Geophys. Geosyst., 11, Q05W05, doi:10.1029/ 2009GC002970.

Conrad, C. P., and B. H. Hager (1999), Effects of plate bending and fault strength at subduction zones on plate dynamics, J. Geophys. Res., 104(B8), 17,551-17,571.

Conrad, C. P., and B. H. Hager (2001), Mantle convection with strong subduction zones, Geophys. J. Int., 144(2), 271-288.

Conrad, C. P., and C. Lithgow-Bertelloni (2002), How mantle slabs drive plate tectonics, Science, 298(5591), 207-209.

Conrad, C. P., and C. Lithgow-Bertelloni (2004), The temporal evolution of plate driving forces: Importance of "slab suction" versus "slab pull" during the Cenozoic, J. Geophys. Res., 109, B10407, doi:10.1029/2004JB002991.

Crameri, F., P. J. Tackley, I. Meilick, T. V. Gerya, and B. J. P. Kaus (2012), A free plate surface and weak oceanic crust produce single-sided subduction on Earth, Geophys. Res. Lett., 39, L03306, doi:10.1029/2011GL050046.

Crowley, J. W., and R. J. O'Connell (2012), An analytic model of convection in a system with layered viscosity and plates, Geophys. J. Int., 188, 61-78, doi:10.1111/j.1365-246X.2011.05254.X.

DeMets, C., R. G. Gordon, D. F. Argus, and S. Stein (1994), Effect of recent revisions to the geomagnetic reversal time scale on estimates of current plate motions, Geophys. Res. Lett., 21(20), 2191-2194.

Dohrmann, C., and P. Bochev (2004), A stabilized finite element method for the Stokes problem based on polynomial pressure projections, Int. J. Numer. Methods Fluids, 46, 183-201, doi:10.1002/fld.752.

Dziewonski, A. M., and D. L. Anderson (1981), Preliminary reference Earth model, Phys. Earth Planet. Inter., 25(4), 297-356.

Elman, H. C., D. J. Silvester, and A. J. Wathen (2005), Finite Elements and Fast Iterative Solvers With Applications in Incompressible Fluid Dynamics, Oxford Univ. Press, Oxford, U. K.

Elsasser, W. M. (1969), Convection and stress propagation in the upper mantle, in The Application of Modern Physics to the Earth and Planetary Interiors, edited by S. Runcorn, pp. 1-41, Wiley-Intersci., Hoboken, N. J.
Enns, A., T. W. Becker, and H. Schmeling (2005), The dynamics of subduction and trench migration for viscosity stratification, Geophys. J. Int., 160, 761-775, doi:10.1111/j.1365-246X.2005.02519.x.

Faccenda, M., L. Burlini, T. V. Gerya, and D. Mainprice (2008), Faultinduced seismic anisotropy by hydration in subducting oceanic plates, Nature, 455, 1097-1101, doi:10.1038/NGEO656.

Forte, A. (2007), Constraints on seismic models from other disciplinesImplications for mantle dynamics and composition, in Treatise on Geophysics, vol. 1, Seismology and the Structure of the Earth, edited by B. Romanowicz and A. Dziewonski, pp. 805-858, Elsevier, Amsterdam.

Fukao, Y., and M. Kikuchi (1987), Source retrieval for mantle earthquakes by iterative deconvolution of long-period P-waves, Tectonophysics, 144(1-3), 249-269.

Funiciello, F., C. Faccenna, A. Heuret, S. Lallemand, E. D. Giuseppe, and T. W. Becker (2008), Trench migration, net rotation and slab-mantle coupling, Earth Planet. Sci. Lett., 271, 233-240, doi:10.1016/j.epsl.2008. 04.006 .

Gee, M. W. C. M. Siefert, J. J. Hu, R. S. Tuminaro, and M. G. Sala (2006) ML 5.0 smoothed aggregation user's guide, Tech. Rep. SAND2006-2649, Sandia Natl. Lab., Livermore, Calif.

Ghosh, A., and W. E. Holt (2012), Plate motions and stresses from global dynamic models, Science, 335, 838-843, doi:10.1126/science.1214209.

Gordon, R. G. (1998), The plate tectonic approximation: Plate nonrigidity, diffuse plate boundaries, and global plate reconstructions, Annu. Rev. Earth Planet. Sci., 26, 615-642.

Grevemeyer, I., N. Kaul, J. L. Diaz-Naveas, H. W. Villinger, C. R. Ranero, and C. Reichert (2005), Heat flow and bending-related faulting at subduction trenches: Case studies offshore of Nicaragua and Central Chile, Earth Planet. Sci. Lett., 236, 238-248, doi:10.1016/j.epsl.2005.04.048.

Gripp, A. E., and R. G. Gordon (2002), Young tracks of hotspots and current plate velocities, Geophys. J. Int., 150, 321-361.

Gudmundsson, O., and M. Sambridge (1998), A regionalized upper mantle (RUM) seismic model, J. Geophys. Res., 103(B4), 7121-7136.

Gurnis, M., and B. Hager (1988), Controls on the structure of subducted slabs, Nature, 335, 317-321.

Gurnis, M., S. Zhong, and J. Toth (2000a), On the competing roles of fault reactivation and brittle failure in generating plate tectonics from mantle convection, in The History and Dynamics of Global Plate Motions, Geophys. Monogr. Ser., vol. 121, edited by M. A. Richards, R. G. Gordon, and R. D. van der Hilst, pp. 73-94, AGU, Washington, D. C.

Gurnis, M., J. Ritsema, H.-J. van Heijst, and S. Zhong (2000b), Tonga slab deformation: The influence of a lower mantle upwelling on a slab in a young subduction zone, Geophys. Res. Lett., 27(16), 2373-2376.

Gurnis, M., C. Hall, and L. Lavier (2004), Evolving force balance during incipient subduction, Geochem. Geophys. Geosyst., 5, Q07001, doi:10.1029/2003GC000681.

Hebert, L. B., P. Antoshechkina, P. Asimow, and M. Gurnis (2009) Emergence of a low-viscosity channel in subduction zones through the coupling of mantle flow and thermodynamics, Earth Planet. Sci. Lett., 278, 243-256, doi:10.1016/j.epsl.2008.12.013.

Hirth, G., and D. Kohlstedt (2003), Rheology of the upper mantle and the mantle wedge: A view from the experimentalists, in Inside the Subduction Factory, Geophys. Monogr. Ser., vol. 138, edited by J. Eiler, pp. 83-105, AGU, Washington, D. C.

Holt, W. (1995), Flow fields within the Tonga slab determined from the moment tensors of deep earthquakes, Geophys. Res. Lett., 22(8), 989992.

Isacks, B., and P. Molnar (1971), Distribution of stresses in descending lithosphere from a global survey of focal mechanism solutions of mantle earthquakes, Rev. Geophys., 9(1), 103-174.

Jadamec, M. A., and M. I. Billen (2010), Reconciling surface plate motions with rapid three-dimensional mantle flow around a slab edge, Nature, 456 , 338-342, doi:10.1038/nature09053.

Jarrard, R. D. (1986), Relations among subduction parameters, Rev. Geophys., 24(2), 217-284

Judge, A. V., and M. K. McNutt (1991), The relationship between plate convergence and elastic plate thickness: A study of the Peru-Chile trench, J. Geophys. Res., 96(B10), 16,625-16,639.

Kanamori, H., D. L. Anderson, and T. H. Heaton (1998), Frictional melting during the rupture of the 1994 Bolivian earthquake, Science, 279(5352), 839-842.

Karato, S., and B. B. Karki (2001), Origin of lateral variation of seismic wave velocities and densities in the deep mantle, J. Geophys. Res., 106(B10), 21,771-21,783

Karato, S., and P. Wu (1993), Rheology of the upper mantle: A synthesis, Science, 260(5109), 771-778.

Kikuchi, M., and H. Kanamori (1995), The Shikotan earthquake of October 4, 1994: Lithosphere earthquake, Geophys. Res. Lett., 22, 1025-1028. 
Kohlstedt, D. L., B. Evans, and S. J. Mackwell (1995), Strength of the lithosphere: Constraints imposed by laboratory experiments, J. Geophys. Res., 100(B9), 17,587-17,602.

Kreemer, C., W. E. Holt, and A. J. Haines (2003), An integrated globa model of present-day plate motions and plate boundary deformation, Geophys. J. Int., 154, 8-34.

Kreemer, C., D. A. Lavallée, G. Blewitt, and W. E. Holt (2006), On the stability of a geodetic no-net-rotation frame and its implication for the International Terrestrial Reference Frame, Geophys. Res. Lett., 33 , L17306, doi:10.1029/2006GL027058.

Lallemand, S., A. Heuret, and D. Boutelier (2005), On the relationships between slab dip, back-arc stress, upper plate absolute motion, and crusta nature in subduction zones, Geochem. Geophys. Geosyst., 6, Q09006, doi:10.1029/2005GC000917.

Li, C., R. D. van der Hilst, E. R. Engdahl, and S. Burdick (2008), A new global model for P wave speed variations in Earth's mantle, Geochem. Geophys. Geosyst., 9, Q05018, doi:10.1029/2007GC001806.

Liu, L., and D. R. Stegman (2011), Segmentation of the farallon slab, Earth Planet. Sci. Lett., 311, 1-10, doi:10.1016/j.eps1.2011.09.027.

Long, M. D., and T. W. Becker (2010), Mantle dynamics and seismic anisotropy, Earth Planet. Sci. Lett., 297, 341-354, doi:10.1016/j.epsl. 2010.06.036.

Long, M. D., and P. G. Silver (2008), The subduction zone flow field from seismic anisotropy: A global view, Science, 319, 315-318, doi:10.1126/ science. 1150809 .

Long, M. D., and P. G. Silver (2009), Mantle flow in subduction systems: The subslab flow field and implications for mantle dynamics, J. Geophys. Res., 114, B10312, doi:10.1029/2008JB006200.

Moresi, L., and M. Gurnis (1996), Constraints on the lateral strength of slabs from three-dimensional dynamic flow models, Earth Planet. Sci. Lett., 138(1-4), 15-28.

Müller, R. D., M. Sdrolias, C. Gaina, and W. R. Roest (2008), Age, spreading rates, and spreading asymmetry of the world's ocean crust, Geochem. Geophys. Geosyst., 9, Q04006, doi:10.1029/2007GC001743.

Nothard, S., J. Haines, and J. Jackson (1996), Distributed deformation in the subducting lithosphere at Tonga, Geophys. J. Int., 127, 328-338.

Paige, C. C., and M. A. Saunders (1975), Solution of sparse indefinite systems of linear equations, SIAM J. Numer. Anal., 12(4), 617-629.

Parmentier, E. M., D. L. Turcotte, and K. E. Torrance (1976), Studies of finite amplitude non-Newtonian thermal convection with application to convection in the Earth's mantle, J. Geophys. Res., 81(11), 1839-1846.

Ranalli, G. (1995), Rheology of the Earth, 2nd Ed., Chapman and Hall, New York.

Ranero, C., J. P. Morgan, K. McIntosh, and C. Reichert (2003), Bendingrelated faulting and mantle serpentinization at the Middle America trench, Nature, 425, 367-373.

Ribe, N. M. (1992), The dynamics of thin shells with variable viscosity and the origin of toroidal flow in the mantle, Geophys. J. Int., 110, 532-552.

Ricard, Y., C. Doglioni, and R. Sabadini (1991), Differential rotation between lithosphere and mantle: A consequence of lateral mantle viscosity variations, J. Geophys. Res., 96, 8407-8415.

Richards, M. A., W.-S. Yang, J. R. Baumgardner, and H.-P. Bunge (2001), Role of a low-viscosity zone in stabilizing plate tectonics: Implications for comparative terrestrial planetology, Geochem. Geophys. Geosyst., 2(8), 1026, doi:10.1029/2000GC000115.

Ritsema, J., H. van Heijst, and J. Woodhouse (2004), Global transition zone tomography, J. Geophys. Res., 109, B02302, doi:10.1029/2003JB002610.

Ruff, L. J. (1999), Dynamic stress drop of recent earthquakes: Variations within subduction zones, Pure Appl. Geophys., 154, 409-431.
Schmandt, B., and E. Humphreys (2010), Complex subduction and smallscale convection revealed by body-wave tomography of the western United States upper mantle, Earth Planet. Sci. Lett., 297, 435-445, doi:10.1016/j.epsl.2010.06.047.

Schubert, G., D. L. Turcotte, and P. Olson (2001), Mantle Convection in the Earth and Planets, Cambridge Univ. Press, Cambridge, U. K.

Spasojevic, S., M. Gurnis, and R. Sutherland (2010), Mantle upwellings above slab graveyards linked to the global geoid lows, Nat. Geosci., 3(6), 435-438, doi:10.1038/NGEO855.

Stadler, G., M. Gurnis, C. Burstedde, L. C. Wilcox, L. Alisic, and O. Ghattas (2010), The dynamics of plate tectonics and mantle flow: From local to global scales, Science, 329, 1033-1038, doi:10.1126/science.1191223.

Stegman, D. R., J. Freeman, W. Schellart, L. Moresi, and D. May (2006), Influence of trench width on subduction hinge retreat rates in 3-D models of slab rollback, Geochem. Geophys. Geosyst., 7, Q03012, doi:10.1029/ 2005 GC001056.

Stoddard, P. R., and D. Abbott (1996), Influence of the tectosphere upon plate motion, J. Geophys. Res., 101, 5425-5434.

Tackley, P. J. (2000), Self-consistent generation of tectonic plates in time-dependent, three-dimensional mantle convection simulations: 1. Pseudoplastic yielding, Geochem. Geophys. Geosyst., 1(8), 1021, doi:10.1029/ 2000GC000036.

Torsvik, T. H., B. Steinberger, M. Gurnis, and C. Gaina (2010), Plate tectonics and net lithosphere rotation over the past $150 \mathrm{My}$, Earth Planet. Sci. Lett., 291, 106-112, doi:10.1016/j.epsl.2009.12.055.

Uyeda, S., and H. Kanamori (1979), Back-arc opening and the mode of subduction, J. Geophys. Res., 84, 1049-1061.

van der Meer, D. G., W. Spakman, D. J. J. van Hinsbergen, M. L. Amaru, and T. H. Torsvik (2009), Towards absolute plate motions constrained by lower-mantle slab remnants, Nat. Geosci., 3, 36-40, doi:10.1038/ NGEO708.

van Keken, P. E., B. Kiefer, and S. M. Peacock (2002), High-resolution models of subduction zones: Implications for mineral dehydration reactions and the transport of water into the deep mantle, Geochem. Geophys. Geosyst., 3, 1056, doi:10.1029/2001GC000256.

van Summeren, J., C. P. Conrad, and C. Lithgow-Bertelloni (2012), The importance of slab pull and a global asthenosphere to plate motions, Geochem. Geophys. Geosyst., 13, Q0AK03, doi:10.1029/2011GC003873.

Vassiliou, M. S., and B. H. Hager (1988), Subduction zone earthquakes and stress in slabs, Pure Appl. Geophys., 128(3-4), 547-624.

Wessel, P., and W. H. F. Smith (1991), Free software helps map and display data, Eos Trans. $A G U, 72,441$

Wiens, D. A., and G. P. Smith (2003), Seismological constraints on structure and flow patterns within the mantle wedge, in Inside the Subduction Factory, Geophys. Monogr. Ser., vol. 138, edited by J. Eiler, pp. 59-81, AGU, Washington, D. C.

Wu, B., C. P. Conrad, A. Heuret, C. Lithgow-Bertelloni, and S. Lallemand (2008), Reconciling strong slab pull and weak plate bending: The plate motion constraint on the strength of mantle slabs, Earth Planet. Sci. Lett., 272, 412-421.

Zhong, S. (2001), Role of ocean-continent contrast and continental keels on plate motion, net rotation of lithosphere, and the geoid, J. Geophys. Res., 106, 703-712.

Zhong, S., and M. Gurnis (1995), Towards a realistic simulation of plate margins in mantle convection, Geophys. Res. Lett., 22(5), 981-984.

Zhong, S., M. Gurnis, and L. Moresi (1998), Role of faults, nonlinear rheology, and viscosity structure in generating plates from instantaneous mantle flow models, J. Geophys. Res., 103(B7), 15,255-15,268. 